\title{
On the usage of geomagnetic indices for data selection in internal field modelling
}

Kauristie, K.; Morschhauser, A.; Olsen, Nils; Finlay, Chris; L. McPherron, R.; Gjerloev, J. W.; Opgenoorth, H. J.

\section{Published in:}

Space Science Reviews

Link to article, DOI:

10.1007/s11214-016-0301-0

Publication date:

2017

Document Version

Peer reviewed version

Link back to DTU Orbit

Citation (APA):

Kauristie, K., Morschhauser, A., Olsen, N., Finlay, C., L. McPherron, R., Gjerloev, J. W., \& Opgenoorth, H. J. (2017). On the usage of geomagnetic indices for data selection in internal field modelling. Space Science Reviews, 206, 61-90. https://doi.org/10.1007/s11214-016-0301-0

\section{General rights}

Copyright and moral rights for the publications made accessible in the public portal are retained by the authors and/or other copyright owners and it is a condition of accessing publications that users recognise and abide by the legal requirements associated with these rights.

- Users may download and print one copy of any publication from the public portal for the purpose of private study or research.

- You may not further distribute the material or use it for any profit-making activity or commercial gain

- You may freely distribute the URL identifying the publication in the public portal 


\title{
On the usage of geomagnetic indices for data selection in internal field modelling
}

\author{
K. Kauristie · A. Morschhauser • N. \\ Olsen - C. Finlay - R. L. McPherron . \\ J. W. Gjerloev · H. J. Opgenoorth
}

the date of receipt and acceptance should be inserted later

\begin{abstract}
We present a review on geomagnetic indices describing global geomagnetic storm activity (Kp, am, Dst and $d D s t / d t)$ and on indices designed to characterize high latitude currents and substorms $(P C$ and $A E$-indices and their variants). The focus in our discussion is in main field modelling, where indices are primarily used in data selection criteria for weak magnetic activity. The publicly available extensive data bases of index values are used to derive joint conditional Probability Distribution Functions (PDFs) for different pairs of indices in order to investigate their mutual consistency in describing quiet conditions. This exercise reveals that $D s t$ and its time derivative yield a similar picture as $K p$ on quiet conditions as determined with the conditions typically used in internal field modelling. Magnetic quiescense at high latitudes is typically searched with the help of Merging Electric Field $(M E F)$ as derived from solar wind observations. We use in our PDF analysis the $P C$-index as a proxy for $M E F$ and estimate the magnetic activity level at auroral latitudes with the $A L$-index. With these boundary conditions we conclude that the quiet time conditions that are typically used in main field modelling $(P C<0.8, K p<2$ and $|D s t|<30 n T)$ correspond to weak auroral electrojet activity quite well: Standard size substorms are unlikely to happen, but other type of activations
\end{abstract}

K. Kauristie

Finnish Meteorological Institute, Helsinki, Finland, E-mail: Kirsti.Kauristie@fmi.fi

A. Morschhauser

GFZ German Research Centre for Geosciences, Potsdam, Germany

N. Olsen

DTU Space,National Space Institute, Technical University of Denmark, Denmark C. Finlay

DTU Space,National Space Institute, Technical University of Denmark, Denmark

R. L. McPherron

University of California, Los Angeles, USA

J. W. Gjerloev

Johns Hopkins University, Maryland, USA

H. J. Opgenoorth

Swedish Institute of Space Physics, Uppsala, Sweden 
(e.g. pseudo breakups $A L>-300 n T$ ) can take place, when these criteria prevail. Although $A E$-indices have been designed to probe electrojet activity only in average conditions and thus their performance is not optimal during weak activity, we note that careful data selection with advanced $A E$-variants may appear to be the most practical way to lower the elevated RMS-values which still exist in the residuals between modelled and observed values at high latitudes. Recent initiatives to upgrade the $A E$-indices, either with a better coverage of observing stations and improved baseline corrections (the SuperMAG concept) or with higher accuracy in pinpointing substorm activity (the Midlatitude Positive Bay -index) will most likely be helpful in these efforts.

Keywords Indices

\section{Introduction}

Scanning photometer data collected during the Canadian ISIS II satellite mission in early 1970's revealed for the first time that the magnetic poles of the Earth are surrounded by persistent auroral ovals (Lui and Anger 1973). Ionospheric and magnetospheric processes maintaining the ovals and associated current systems have been probed continously since the ISIS II days with numerous multipurpose satellite programs and tailored science missions (for a listing of relevant satellite missions, see e.g. Tsyganenko (2002)). In a large scale picture the magnetospheric current systems consist of the ChapmanFerraro currents at the magnetopause, of two solenoidal current systems in the magnetotail including the cross-tail current and the westward ring current flowing in the nightside near-Earth region (at geocentric distance of 3-4 Earth radii). The magnetosphere and high-latitude ionosphere are coupled with each other with currents flowing along the geomagnetic field lines (Field Aligned Currents, FACs): The Region 1 and Region 2 FACs link the poleward and equatorward boundaries of auroral oval to the low latitude boundary layer and ring current region of magnetosphere. During auroral substorms part of the cross tail current gets diverted as Substorm Current Wedge (SCW) (McPherron 1979) to the ionosphere, where it causes abrupt enhancements of westward currents in the midnight sector of oval. At low and middle latitudes the strongest ionospheric currents, Solar quiet $\left(S_{q}\right)$ and equatorial electrojet currents, are driven by direct solar activity.

The sequence of Ørsted (1999-2014), SAC-C (2000-2013), and CHAMP (2000-2010) satellites catalyzed extensive usage of space-based data in internal (main) magnetic field modelling. These missions have also enhanced collaboration between external and internal field research communities. External field researchers need easily adoptable internal field models as inward extension to empirical magnetospheric field models or simulations. A holistic view of magnetic field topology is necessary also when searching magnetic conjugacy events in combined analysis of ionospheric and magnetospheric observations. Reciprocally, when internal magnetic field models are constructed, an appropriate description for the external field is needed in order to discriminate it accurately 
from the internal signal. The multi-satellite concept of the ESA Swarm mission (Friis-Christensen et al. 2006), which became available in November 2013, is of high interest for both research communities, because it allows for the first time measurements of longitudinal gradients both in ionospheric processes and in sub-surface structures.

The International Geomagnetic Reference Field (IGRF) is the most widely known main field model outside the internal field modelling community. IGRF is a spherical harmonic reference model for the main features of internal field developed as international collaboration under the coordination of the International Association of Geomagnetism and Aeronomy (IAGA) Division V Working Group. IGRF is updated once in every five years. The processes to determine the two latest releases of IGRF coefficients, IGRF-11 and IGRF-12, are described by Finlay et al. (2010) and Thébault et al. (2015). The work begins with a call for candidate models to which typically some 7-9 international teams respond with proposals for a definitive reference field for the 5 years preceding the previous call, for provisional field for the latest 5-year epoch and for a predictive secular variation field model for the coming 5-year epoch. The candidate models are evaluated by a task force nominated by the IAGA Division V. Based on the evaluation results the task force decides how the different candidates are weighed in the computation of the coefficients for the final releases.

The coefficients for IGRF candidate models are in many cases based on well established high precision parent models, e.g. in the case of IGRF-11, where some of the candidates were derived from the basis of CHAOS-3, POMME-6, and GRIMM-2 models. The field models are derived from a magnetic scalar potential which obeys the Laplace's equation and thus can be expressed as a spherical harmonic expansion weighted by Gauss coefficients and with a time dependence characterizing the secular variation of the field. The CHAOS models are named according to their data sources which are CHAMP, Ørsted, and SAC-C satellites together with magnetic observatories belonging to the INTERMAGNET network (Olsen et al. 2010). The POMME models have been developed in the GeoForschungsZentrum (GFZ) Potsdam and in the National Geophysical Data Center (NGDC) to support the recurrent IGRF updates and they use CHAMP data (Maus et al. 2010). The GRIMM models come also from GFZ and are based on CHAMP and observatory data (Lesur et al. 2010). Examples of some more recently developed models are the latest version of Comprehensive Model series, CM5, which uses similar data sources to CHAOS, but processes their data with a novel inversion algorithm developed for the Swarm mission (Sabaka et al. 2015) and the Swarm Initial Field Model (SIFM), which is based on Swarm measurements from the first year of the mission (Olsen et al. 2015). For more details about the different internal model families, see the paper by Finlay et al. in this issue.

The use of cleverly selected coordinate systems can significantly facilitate external field parametrization when developing geomagnetic field models. The Solar-Magnetic (SM) coordinate system has appeared to be the most suitable for ring current and magnetopause current parametrization while for magne- 
totail currents the Geocentric-Solar-Magnetospheric (GSM) coordinate frame is a more appropriate way for data modeling (Maus and Lühr 2005; Olsen et al. 2006) (for the introduction of SM and GSM coordinates, see Kivelson and Russell (1995)). The Quasi-Dipolar (QD) coordinate system introduced by Richmond (1995) is a good framework to represent ionospheric currents and FACs which still at Low Earth Orbit (LEO) altitudes are organized according to the ambient magnetic field whose topology can be described accurately enough with IGRF models (Sabaka et al. 2015). Replacing magnetic londitudes with Magnetic Local Time (MLT) helps in distinguishing such features in ionospheric currents that depend on the location of sub-solar point with respect to the magnetic pole (Baker and Wing 1989). QD-latitudes \pm 60 or 55 are often used as the demarcation between polar and non-polar areas which are handled differently in data processing (Olsen et al. 2006; Lesur et al. 2010; Olsen et al. 2015).

Besides using correct coordinate systems also applying carefully considered data selection criteria is a common way to control the variablity of external sources in internal field estimation. The impact from solar driven ionospheric currents at low and mid-latitudes is reduced by using only measurements from regions where the Sun has been below the horizon. In polar areas the field variations due to FACs are able to cause a small distortion to the magnetic field direction but their impact to the field intensity is insignificant. Therefore, perturbations due to FACs can be avoided by using only total field data instead of vector measurements. Periods of low external activity can be searched by studying the variations in geomagnetic indices based on ground-based observatory data. Indices which characterize the intensity of geomagnetic storms, like $K p, a m, D s t$, and $d D s t / d t$ (definitions given later in this article), are used to describe the impact of magnetospheric currents, while the strength of high-latitude ionospheric currents is estimated either with the help of Interplanetary Magnetic Field $(I M F)$ or by estimating the energy transfer from solar wind to magnetosphere with the dayside Merging Electric Field $(M E F)$. $M E F$ depends on $I M F$ and on the solar wind velocity and it is closely related to the Polar Cap $(P C)$ index (both discussed in more detail below).

The different modelling initiatives have used geomagnetic indices in their data processing in several ways. The $D s t$ index (or its refined version, the RC index) and its time derivative are used to search magnetically quiet periods and to characterize time variations in the external field with its induction effect (Maus and Lühr 2005; Olsen et al. 2005b). Magnetically quiet times are associated with the conditions of $|D s t|<30 n T$ and $|d D s t / d t|$ or $|d R C / d t|$ being less than 2 or $5 n T / h$ (Olsen et al. 2014; Maus et al. 2010; Sabaka et al. 2015). CHAOS, CM-5 and SIFM characterize weak global activity with the condition $K p \leq 2^{\circ}$ (Olsen et al. 2006; Sabaka et al. 2015; Olsen et al. 2015). POMME-6 uses the $a m$ index instead of $K p$ with the limits $a m<12$ for mid latitudes and $a m<27$ for high latitudes (Maus et al. 2010). The conditions used for $I M F$ and $M E F$ correspond to situations where dayside merging is minimal and consequently auroral electrojets and polar cap currents are weak. This happens when $I M F$ does not have a strong antiparallel component with 
the geomagnetic field at dayside magnetopause or poleward of the cusp (e.g. $-2 n T<B_{z}<6 n T$ and $\left|B_{y}\right|<8 n T$ Maus et al. (2010)). For $M E F$ (or for its revised version by Newell et al. (2007)) a typical condition for weak electrojet activity is $M E F<0.8 \mathrm{mV} / \mathrm{m}$ (Olsen et al. 2014; Maus et al. 2010; Sabaka et al. 2015).

It is noteworthy that the Auroral Electrojet $(A E)$ indices (Davis and Sugiura 1966) have not been used extensively in quiet time data selection criteria, although in principle they should provide a more comprehensive description on auroral currents than $M E F$ or $I M F$ alone can provide. The prime reason for this is that $A E$-indices include also the impact from SCW activations in the midnight sector. The absence of $A E$ in data selection criteria of internal field models is motivated by the statistical study of Ritter et al. (2004) which shows that the above given condition for MEF particularly in winter time gives better results than any of the tested geomagnetic indices when searching low RMS values for the residuals between field intensity observations and a field model.

In this review we describe how geomagnetic indices can be associated with various external current systems and how they relate to each other during weak activity. We study how consistently the different indices characterize quiet conditions. In addition, pros and cons of $A E$-indices and their variants are discussed. The first sections of this paper give a review on $D s t, K p, A E$ and $P C$ indices. In the latter part of the paper we present joint Probability Distribution Functions (PDF) for different index pairs and discuss challenges and advancements in pinpointing substorms with $A E$-type indices whose performance is compared with that of the recently published Midlatitude Positive Bay index (Chu et al. 2014, 2015) designed to measure the strength of FACs in SCW.

\section{The different index families}

Several indices have been developed for characterizing the level of magnetic field contributions from ionospheric and magnetospheric sources. They can be classified in various groups depending on the phenomena they aim to characterize. Mayaud (1980), Siebert and Meyer (1996) and Menvielle et al. (2010) provide extensive reviews of the various indices.

\subsection{The $K_{p}$-index and global activity $(K p, a p, A p, a a)$}

$K p$ is a 3-hour index that aims at describing the global level of "all irregular disturbances of the geomagnetic field caused by solar particle radiation within the 3-hour interval concerned" (Siebert and Meyer 1996). It was introduced by Julius Bartels in 1938 and adopted by IAGA in 1951. Kp is derived from (currently) 13 sub-auroral stations, the location of which is shown by green dots in Figure 1. For each of these observatories, the disturbance level 


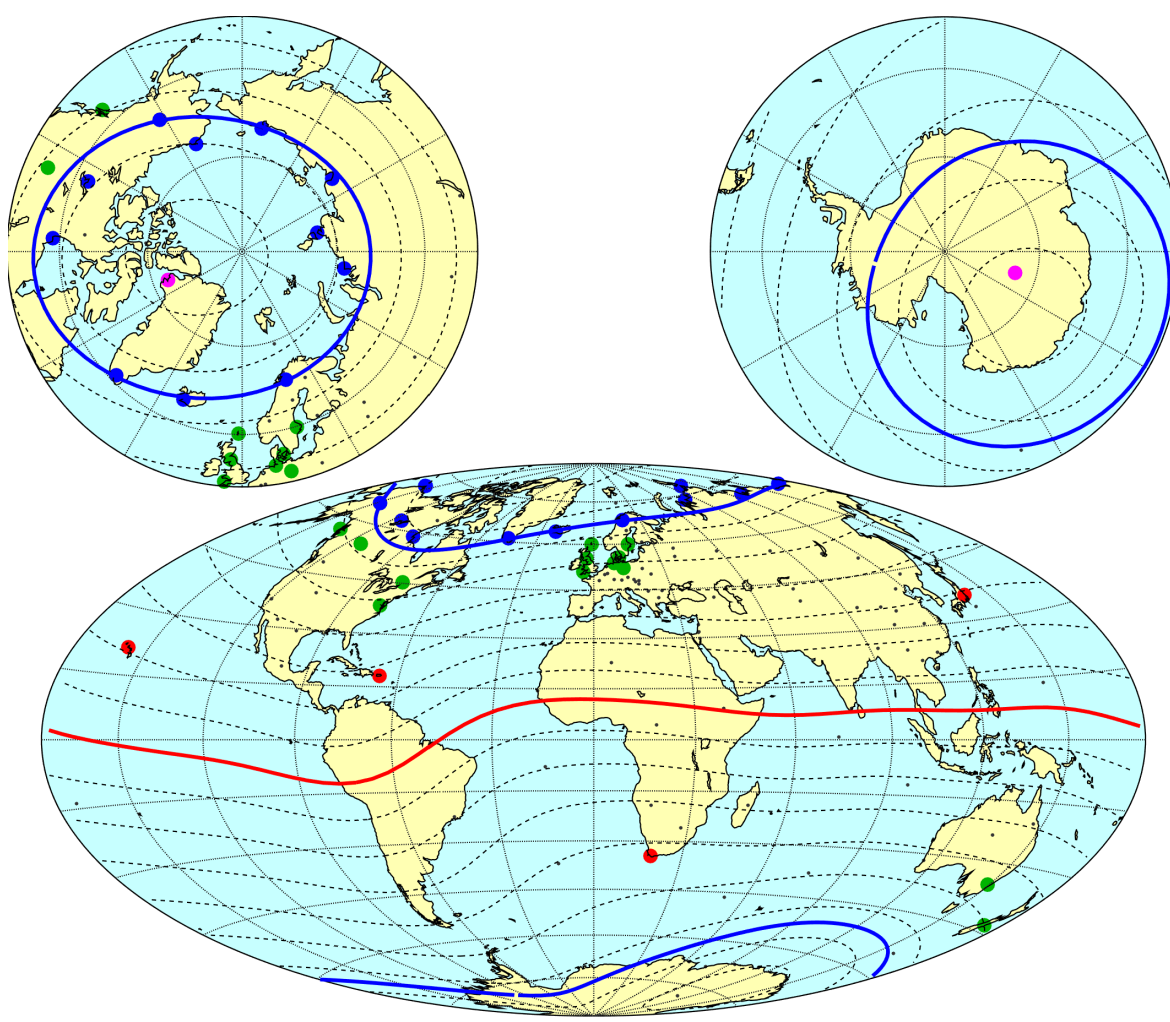

Fig. 1 Geographical distribution of geomagnetic observatories contributing to the indices Dst (red), Kp (green), AE (blue), and PC (magenta). Dashed lines show magnetic latitude in steps of $10^{\circ}$. Highlighted are $\pm 65^{\circ}$ latitude (blue line) and the dip-equator $\left(0^{\circ}\right.$, red line).

at that site is determined by measuring the range $a$ (i.e. the difference between the highest and lowest values) during three-hourly time intervals (in UT) for the most disturbed horizontal magnetic field component, after removing of the regular daily variation, $S_{R}$, as sketched in Figure 2 . In the official $K p$ procedure $S_{R}$ is determined manually according to the guidance of Mayaud (IAGA Bulletin 21, 1967). In automated $K p$ variants the $S_{R}$ curve is estimated e.g. with the mean daily variation of the 5 quietest days of each month. The range $a$ is then converted to a $K$ value of the given 3 -hour interval, taking values between 0 (quietest) and 9 (most disturbed) on a quasilogarithmic scale. This scale was first determined for the Niemegk observatory (Menvielle and Berthelier 1991). For the other observatories the lower boundary for $K=9$ level has been determined so that in long run, statistically, the occurrence probability of $K=9$ is same as in Niemegk. The boundaries for other $K$-levels are then determined so that they are proportional to the corresponding Niemegk boundaries with the same factor as used for $K=9$ (Mayaud 1980). The $K$ values are converted to a standardized number, de- 


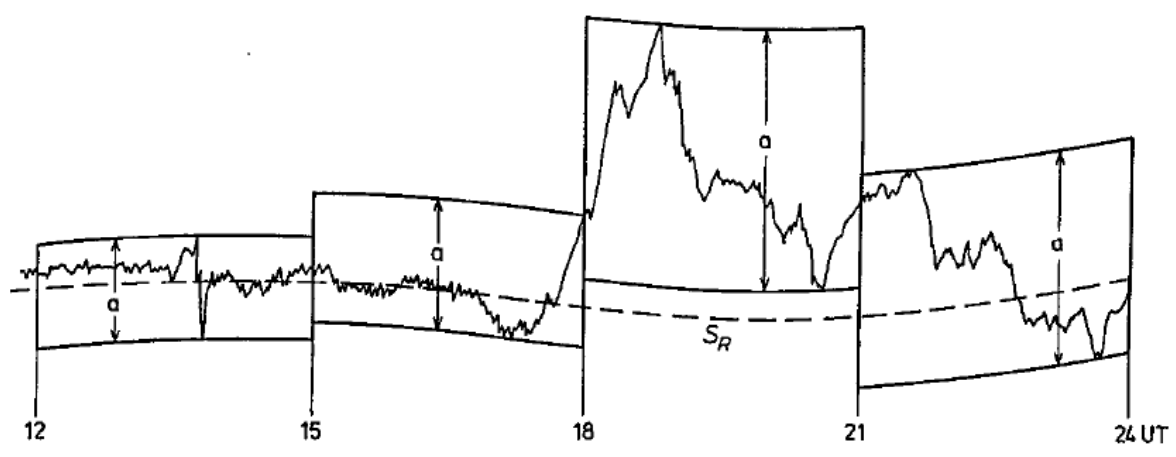

Fig. 2 Schematic magnetogram for four 3-hour intervals, illustrating the elimination of the regular daily variation, $S_{R}$ (dashed curve). The maximum disturbance range $a$ of each 3-hour interval is defined as the difference between the upper and lower envelopes of the magnetogram parallel to $S_{R}$. After Siebert and Meyer (1996).

noted as $K s$, using conversion tables based on the statistical properties of $K$ at the observatory in consideration. Details about the $K p$ procedure with the conversion tables are available in http://www.gfz-potsdam.de/en/section/ earths-magnetic-field/data-products-services/kp-index/explanation/. $K s$ is given in a scale of thirds, ranging through 28 grades in the order $0^{\circ}, 0^{+}, 1^{-}, 1^{o}, 1^{+}, 2^{-}, 2^{o}, 2^{+}, \ldots, 8^{o}, 8^{+}, 9^{-}, 9^{\circ}$. The planetary activity index $K p$ is the mean of the $K s$ value of the (originally 11, presently 13) " $K p$ stations".

A derived quantity is the three-hour index $a p$, which is a linearized version of $K p$ converted using the following table:

$\begin{array}{lcccccccccccccc}K p & 0^{o} & 0^{+} & 1^{-} & 1^{o} & 1^{+} & 2^{-} & 2^{o} & 2^{+} & 3^{-} & 3^{o} & 3^{+} & 4^{-} & 4^{o} & 4^{+} \\ a p & 0 & 2 & 3 & 4 & 5 & 6 & 7 & 9 & 12 & 15 & 18 & 22 & 27 & 32 \\ K p & 5^{-} & 5^{o} & 5^{+} & 6^{-} & 6^{o} & 6^{+} & 7^{-} & 7^{o} & 7^{+} & 8^{-} & 8^{o} & 8^{+} & 9^{-} & 9^{o} \\ a p & 39 & 48 & 56 & 67 & 80 & 94 & 111 & 132 & 154 & 179 & 207 & 236 & 300 & 400\end{array}$

For a station at about $\pm 50^{\circ}$ magnetic latitude, ap may be regarded as the range of the most disturbed of the two horizontal field components, expressed in the unit of $2 \mathrm{nT}$ (Lincoln 1967). The daily average of the 8 three-hour values of $a p$ is denoted as $A p$. The $a m$ index is a variant of $a p$ based on a more extensive network of measurement stations (Mayaud 1980). am is available for years 1959-1996.

Time series of solar and geomagnetic activity, as measured by the International sunspot number $R$, respectively $A p$, are shown in Figure 3. While years of minima in solar activity coincide with years of minima in geomagnetic activity, there is an obvious phase shift of the maximum; highest geomagnetic activity typically occurs roughly two years after the solar activity maximum.

The left panel of Figure 4 shows the probability (normalized histogram) of $K p$, for the geomagnetically quiet year 1997 (in red), for the active year 2003 (in yellow) and for all years between 1980 and 2015 (in blue). The corresponding cumulative distribution functions are shown in the right part of the Figure. The most likely value of $K p$ is considerably higher for an active year. Perhaps 


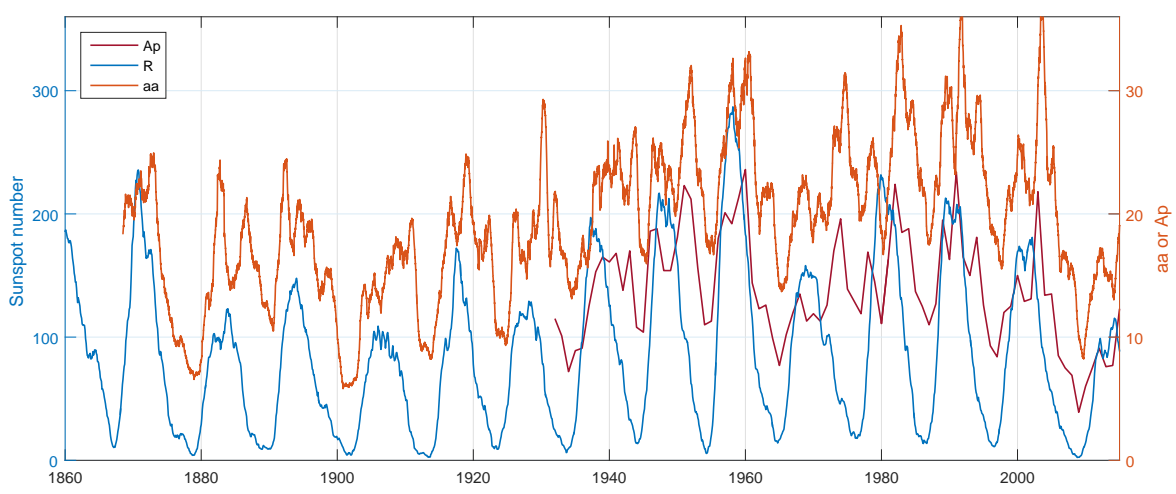

Fig. 3 Time series of solar activity as measured by the International sunspot number (blue, left axis) and of geomagnetic activity as measured by $A p$ (magenta, right axis) and $a a$ (red, right axis).
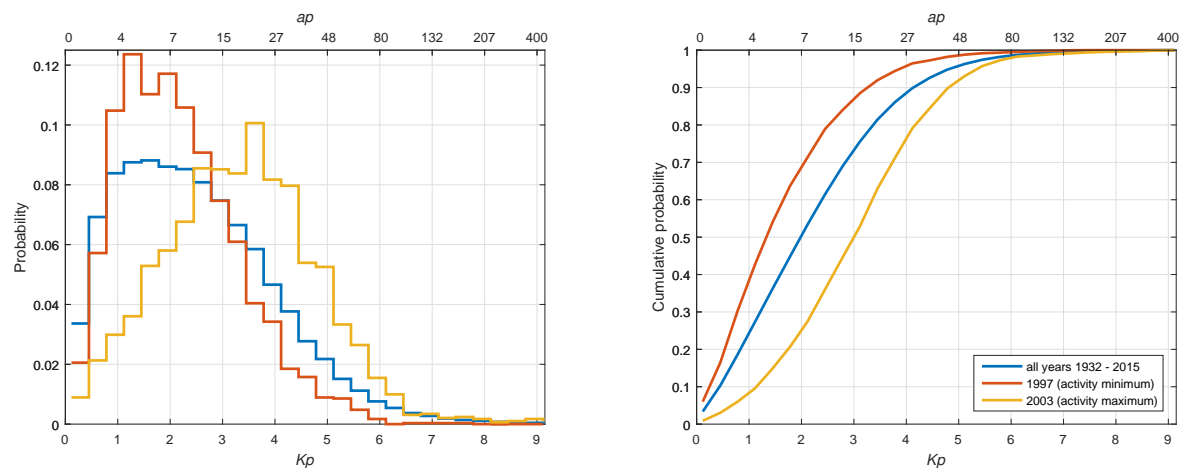

Fig. 4 Probability distribution (left) and cumulative probability distribution (right) of $K p$ (left), for various conditions of solar activity.

even more important is the fact that $K p \leq 2^{\circ}$ occurs for $70 \%$ of the time in a quiet year, but only for $25 \%$ of the time during a disturbed year, with an average of $50 \%$ for all years.

The five most quiet, or respectively most disturbed, days of each month are determined from the sum of the eight values of $K p$, the sum of the square of $K p$, and the largest value of $K p$ using an algorithm described e.g. in Menvielle et al. (2010). Note that this classification of "quiet" and "disturbed" is relative, since the five most quietest, respectively disturbed, days are found, irrespectively of the absolute level of activity. As a consequence, the mean $A p$ of the quietest days, $\overline{A p}$, of an active year like 2003 (with $\overline{A p}=8.6$ ) is higher than the corresponding mean value for a quiet year like $1997(\overline{A p}=3.4)$. It turns out that the average $A p$ for all but the five most disturbed days of each month in 1997 is lower $((\overline{A p}=6.7)$ than the mean value of the five quietest days of the year 2003 ! 
$K p$, ap and $A p$ are calculated bi-weekly and are available since 1932. They are provided at http://www.gfz-potsdam.de/pb2/pb23/niemegk/kp_ index/.

In an attempt to monitor global geomagnetic activity at times prior to 1932 (the year since when $K p$ is available), Mayaud (1971) introduced the $a a$ index. $a a$ is calculated from the $K$ indices of the two nearly antipodal magnetic observatories Greenwich/Abinger/Hartland in England and Melbourne/Toolangi/Canberra in Australia and goes back to 1868. Annual running mean values of $a a$ are shown in Figure 3. Note the offset between $a a$ and $A p$; the two indices therefore need to be scaled in order to be comparable.

Nevanlinna and Kataja (1993) derived an activity index from magnetic observations taken at the Helsinki geomagnetic observatory. Starting in 1844, this index extends the aa series back in time by two solar cycles. These data have been used e.g. by Lockwood et al. (2013) to investigate near-Earth interplanetary conditions over the past 170 years. Svalgaard (2014) recently argued for the necessity to re-calibrate the historical data from the Helsinki observatory in order to obtain an index of geomagnetic activity that is homogenous in time, otherwise there is risk for spurious long-term trends of geomagnetic activity.

2.2 Indices describing the magnetospheric Ring current ( $D s t$ and its variants)

The Dst index and its variants aim to monitor variations of the equatorial magnetospheric ring current. Such indices are usually derived from the horizontal component $H$ of the geomagnetic field, as measured at ground observatories distant from the auroral and equatorial electrojets and approximately equally distributed in longitude.

There is a long history of studies of geomagnetic storms using rapid variations of the $H$ component. For example, Chapman (1918) studied the common characteristics of 40 storms as revealed by the differences between hourly and monthly mean values of the $H$ component at 12 ground observatories, identifying common characteristics for observatories at high, middle and low latitudes. Following the International Geophysical Year (1957-1958), considerable efforts were made to define a global index for the equatorial ring current, and in 1969 IAGA indorsed a version of the Dst index as proposed by Sugiura (1969). An interesting alternative proposal was also made during this period, based only on night-side data (Kertz 1958, 1964). A detailed history of the Dst index can be found in Sugiura and Kamei (1991).

The standard, and IAGA endorsed, version of Dst (hereafter called KyotoDst in this section) is produced by the WDC for Geomagnetism, Kyoto and is available from 1957 up until present. Here we give a brief summary of its derivation, for full details see Sugiura and Kamei (1991). Kyoto-Dst uses $H$ from four ground observatories, shown as red dots in Figure 1: Hermanus (South Africa), Kakioka (Japan), Honolulu (USA), and San Juan (Puerto Rico), with a good distribution in longitude, and at relatively low latitudes 
while still being sufficiently distant from the ionospheric equatorial electrojet to avoid significant disturbance.

A baseline $H_{\text {base }}$ is defined for $H$ at each observatory using a least-squares fit of a quadratic in time polynomial model to annual means (calculated using the five quietest days of each month) from the current and the five preceding years. In an effort to reduce baseline discontinuities between years, the predicted baseline from the end of the previous year is included as an extra data point in the determination of the baseline for the new year. Nonetheless, baseline discontinuities can still sometimes occur at the start of a year due to the different baseline models for adjacent years. The estimated baseline is then subtracted from $H$ separately at each observatory. Next, an estimate of the solar quiet daily variation $S_{q}$ is determined for each observatory each month, by fitting a double Fourier series (in local time and month) to $H$ from the five quietest days of each month, after correction for the baseline, and after removal of a linear trend based on the night-time values. The disturbance variation $\mathrm{D}(T)$ for any UT hour $T$ at each observatory is then defined to be

$$
\mathrm{D}(T)=H(T)-H_{\text {base }}(T)-S_{q}(T) .
$$

The disturbance variation at each observatory $i, \mathrm{D}_{i}(T)$, is next averaged by summing over the four observatories $i=$ Hermanus, Kakioka, Honolulu, San Juan, taking into account their latitude in geomagnetic dipole co-ordinates $\alpha_{\mathrm{gd}, i}$, to obtain the Kyoto-Dst index, Dst (T):

$$
\operatorname{Dst}(T)=\frac{1}{4} \sum_{i=1}^{4} \frac{\mathrm{D}_{i}(T)}{\cos \alpha_{\mathrm{gd}, i}} .
$$

Kyoto-Dst is available to download from http://wdc.kugi.kyoto-u.ac . jp/dstdir/index.html. In January 2016, Final Dst was available for 19572011, Provisional Dst was available for 2012 to 2014 and March 2015, while Real-time (Quick-look) Dst was available for the remaining months. Final values of Dst are considered definitive, with further changes unlikely, Provisional Dst are computed after screening of observatory data to remove artificial noise sources, while real-time $D s t$ is derived from unverified raw data and may contain some inaccuracies for example due to artificial noise and baseline shifts. Real-time Dst values are gradually replaced by provisional and final values. An example of the Kyoto-Dst for approximately a month around the time of the St. Patrick's day storm of March 2015 is shown in the red line in Figure 5.

Over the years, a number of modified versions of the Dst index have been proposed, each with specific purposes in mind. Here we summarize some of the best known, focusing on those most often used in studies of the quiet-time ring current.

For applications requiring high temporal resolution, the mid-latitude geomagnetic indices $S Y M$ and $A S Y M$ (Iyemori 1990; Wanliss and Showalter 2006) provide estimates of both the longitudinally symmetric and asymmetric parts of the disturbance field, and are available for both $H$ (magnetic north) and $D$ 


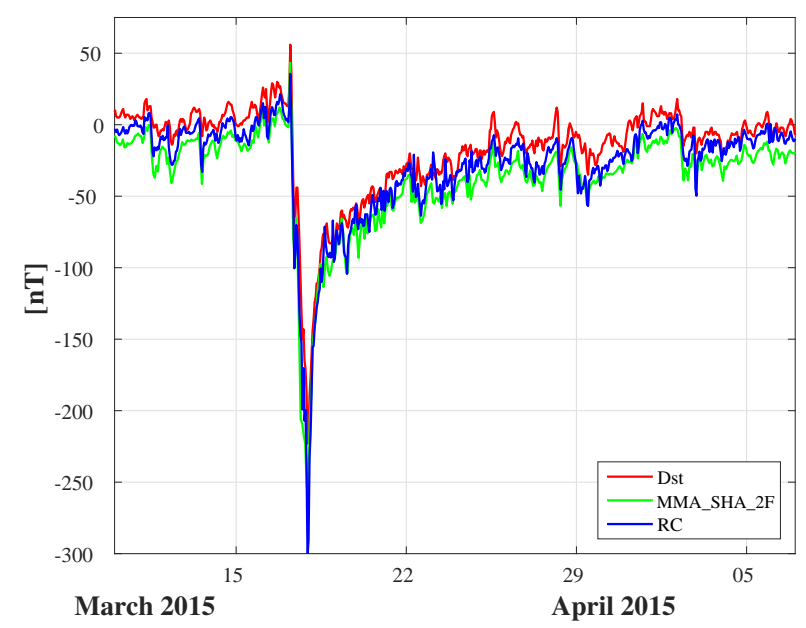

Fig. 5 Comparison of the ground observatory based Dst index (Sugiura and Kamei 1991) in red, the $R C$ index (Olsen et al. 2014), in blue, and the satellite-data based $M M A_{-} S H A_{-} 2 F$ index (Hamilton 2013) in green, for a month around occurrence of the St Patrick's day geomagnetic storm on 17th March 2015.

(magnetic east component). The processing of $S Y M-H$ is essentially the same as that for Kyoto-Dst, but a different selection of ground observatories is used (six are chosen depending on the availability and condition of the data for each month from Honolulu, Kakioka, Alibag, Hermanus and San Juan (as for Kyoto-Dst) and also, from slightly higher latitudes, Urumqi, Fredericksburg, Boulder, Tucson, Memambetsu, Martin de Vivies and Chambon-la-Foret).

A revised version of $D s t$, based on hourly mean data from the same four observatories used in the Kyoto-Dst, but involving in particular a more sophisticated removal of the signature of the $S_{q}$ field, has recently been proposed by USGS (Love and Gannon 2009). A time and frequency domain band stop approach is applied, with periodic variations related to the Earth's rotation, the moons' orbit, the Earth's orbit around the Sun, and their mutual couplings explicitly removed. The baseline removal for this USGS-Dst is also different, based on the five quietest days each month, selected as those with the lowest mean of the absolute hour-to-hour differences each day, and then fit by a Cheybshev polynomial model of degree less than or equal to 10 considering the entire timespan for each observatory. UGSG-Dst is available to download from http://geomag.usgs.gov/products/downloads.php and a minute resolution version has also been developed (Gannon and Love 2011).

In the past decade there has been some discussion of the amplitude of the semi-annual variation in the Kyoto-Dst index (Mursula and Karinen 2005; Svalgaard 2011; Temerin and Li 2015). Karinen and Mursula (2005) proposed a revised index they called $D c x$ which they argue corrects for excessive semiannual variation due to a seasonally-varying quiet level unrelated to magnetic storms. USGS-Dst index also shows less power in the semi-annual variation than does the Kyoto-Dst (Love and Gannon 2009). This issue however re- 
mains controversial, since it is possible that the quiet-time ring current itself does undergo semi-annual variations unrelated to $S_{q}$ and it may be for some applications (e.g. internal field modelling) desirable to keep this part of the signal.

With the demands of fitting high accuracy ground and satellite data, geomagnetic field modellers have also attempted to use $D s t$ to parameterize time-variations of the quiet-time magnetospheric ring current. But Kyoto-Dst is designed for studying disturbed times, not quiet times, so its baseline is not well suited to such applications. To avoid such 'misuse' of the Kyoto-Dst several variants aiming to better capture the quiet-time magnetospheric field have been proposed. One example is the Vector Magnetic Disturbance VDM index (Thomson and Lesur 2007) which uses one-minute data from INTERMAGNET ground observatories with geomagnetic latitudes below 50 degrees, considering only data from dark regions. Considering three month windows, a constant, a linear trend, and then a time-dependent degree 1 spherical harmonic model (with a three day knot spacing), are each removed. Then a second time-dependent degree 1 spherical harmonic model, with one hour knots is fit, and used to define the $V D M$ index that has been used for example in the GRIMM series of field models to parameterize the time-dependence of the large-scale external field (Lesur et al. 2008, 2010).

Another example of a Dst type index designed for internal field modelling is the $R C$ index (Olsen et al. 2014). This has been used to parametrize the time-variations of the near-Earth magnetospheric field in the most recent versions of the CHAOS series of field models. The $R C$ index focuses on having a stable baseline and accounts for secular variation more consistently across observatories by removing a time-dependent core field model. In its latest version (Finlay et al. 2015), $R C$ is derived from 14 mid and low latitude ground observatories Alice Springs (Australia), Boulder (USA), Chambon la Foret (France), Fredericksburg (USA), Guam (Guam), Honolulu (USA), Hermanus (South Africa), Kakioka (Japan), Kourou (French Guiana), Learmouth (Australia), M'bour (Senegal), Niemegk (Germany), San Juan (Puerto Rico) and San Pablo de los Montes (Spain). Contamination from $S_{q}$ sources is avoided as far as possible by considering only night-side data, as previously proposed by Kertz $(1958,1964)$ and more recently advocated by Svalgaard (2005) and Thomson and Lesur (2007). Induced field variations resulting from the $S_{q}$ field acting on the electrically conducting lithosphere and upper mantle may have a small signature (1-5 nT) even in the night sector (Olsen et al. 2005a) that is not accounted for in the derivation of RC. It is presently difficult to remove this signal due to uncertainties in the distribution of electrical conductivity. A comparison of the baseline corrections required within the CHAOS-4 field model in order to match $D s t$ and $R C$ to satellite magnetic data is shown in Figure 6. Note that smaller corrections are needed when using $R C$ compared to $D s t$; considering 30-day running means, the differences between the external parts of $R C$ and Dst (see below) can be as large as $15 \mathrm{nT}$.

To derive the $R C$ index, hourly mean values from the above observatories, checked using the procedure described by Macmillan and Olsen (2013) and 


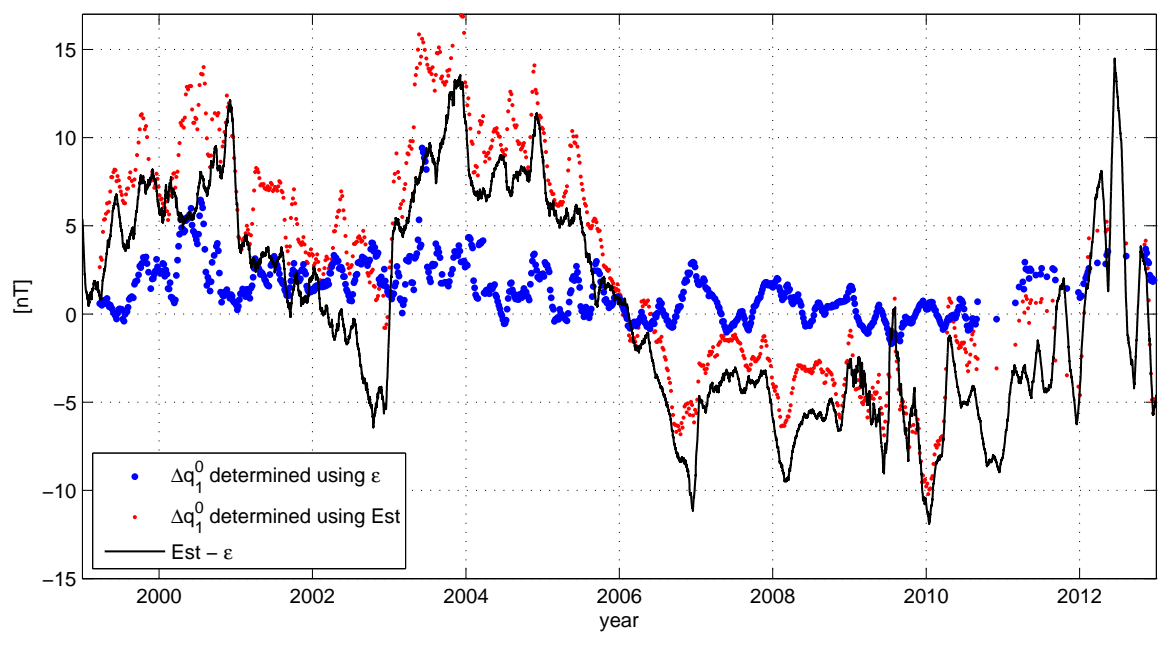

Fig. 6 "Baseline corrections" parameters $\Delta q_{1}^{0}$ required in the CHAOS-4 field model in order to match satellite magnetic data, when using an external field model paramaterized by the $D s t$ or $R C$ indices. Red dots show the corrections required when using the Est (the external part of $D s t$ ), blue dots show the corrections required when using the external part of the $R C$ index (called $\epsilon$ here). Note that baseline corrections are generally much smaller for $R C$ than for Dst. The difference between the external parts of $R C$ and Dst are shown by the black curve. All presented values are 30-day running means. From Olsen et al. (2014).

extracted from the Swarm auxilliary data product AUX_OBS_2 (Geomagnetic observatory data from INTERMAGNET and other observatories), are processed to remove (i) an estimate of the time-dependent core field (up to spherical harmonic degree 20) from the latest version of the CHAOS field model (ii) an estimate of the large-scale static (non-ring current) magnetospheric field from the CHAOS field model (iii) static crustal offsets as estimated at each component at each observatory using the robust mean of all quiet $\left(K p<2^{\circ}\right)$ time data. Then for each hour from January 1st 1997 up to present a dipolar (maximum degree $N=1$ ) spherical harmonic model is fit to the resulting two horizontal component data from as many as possible of the selected observatories. Only data between 18.00 and 08.00 local time (i.e. "night") is used in an effort to minimize the impact of $S_{q}$; no additional explicit $S_{q}$ correction is carried out. The spherical harmonic fit is carried out in geomagnetic dipole coordinates using a robust estimation scheme with Huber weights (Constable 1988). The $R C$ index is then defined to be the spherical harmonic coefficient corresponding to the axial dipole in geomagnetic dipole co-ordinates. This procedure naturally takes account of the varying latitudes of the contributing observatories.

A comparison of the $R C$ (blue line) and Kyoto-Dst (red line) indices is presented in Figure 5. Although their morphology is generally similar, there are some differences between the series. There is a small offset between $R C$ and Kyoto-Dst over this month, most noticeable at quiet times, which likely 
results from the different approaches taken to correct for secular variation. Day-to-day disturbance are similar, but the amplitudes sometimes differ. This may be because $R C$ includes a different selection of observatories than Kyoto$D s t$, and because it only considers observatories within a limited range of local time. The primary advantage $R C$ is the consistent manner in which the secular variation is removed: fitting de-trending polynomials within windows, which is known to result in baseline instabilities for the Dst index (Temerin and $\mathrm{Li} 2015$ ), is avoided. The latest version of the $R C$ index, is available from http://www.spacecenter.dk/files/magnetic-models/RC/current/.

There have also been attempts to produce models/indices describing the near-Earth effects of the magnetospheric ring current, based on magnetic data collected by low Earth orbit satellites, rather than ground data. One example is the Swarm Level 2 product MMA_SHA_2F (Hamilton 2013). This is generated once per orbit, by fitting a degree 1 spherical harmonic model to Swarm magnetic field data, after removal of estimated core, lithosphere and ionospheric contributions. MMA_SHA_2F is also presented in Fig. 5 for comparison with Kyoto-Dst and $R C$. The three indices clearly track the same disturbances, but their baselines (by definition) differ, with MMA_SHA_2F being the most offset to more negative values.

An important issue for global geomagnetic field modelling is the separation of the Dst and its variants into external and induced parts. This is crucial if the predictions of the disturbance time index are to be successfully mapped to satellite altitude (internally-induced components will be weaker at satellite altitudes compared to on ground). Following initial work on this topic by Häkkinen et al. (2002), Maus and Weidelt (2004) and Olsen et al. (2005b) have described techniques to carry out such a separation given knowledge of a 1D electrical conductivity profile within the Earth. The internal, induced, part of Dst is normally referred to as Ist and the external, magnetospheric, part as Est. The VDM and $R C$ indices are also routinely separated into internal (induced) and external parts.

Although its primary applications have been in studies of geomagnetic storms and in attempts to study the magnetospheric ring current, the Dst index, and especially its variants with improved baseline stability (VMD and $R C$ ), are now essential in modern models of the quiet-time geomagnetic field. They are used not only in data selection (via thresholds in the amplitude of Dst or its time rate of change) but to parameterize the near-Earth signatures of ring current fluctuations. Efforts to improve the longitudinal and hemispheric (north vs south) coverage of the observatory data contributing to the Dst-type indices, as well as better removal of ionospheric $\left(S_{q}\right.$ and solar-wind driven disturbances at higher latitudes) and related induced signals, are still needed for these high accuracy applications. 
2.3 The $A E$-indices describing auroral electrojets

\subsubsection{The official AE-indices}

Davis and Sugiura (1966) introduced the Auroral Electrojet indices ( $A E$, $A U, A L, A O)$ with the goal of characterizing global auroral electrojet currents. Their pioneering study demonstrates the usage of $A E$-indices with a data set of H-recordings by 7 auroral stations from 6 days. Already with this relatively limited sample the authors managed to make some interesting conclusions on electrojets behavior: Currents have burst-like activity, the activations tend to repeat with an interval of 4 hours and the most active phase lasts typically 1 hour. Similar repetition rates had been observed in magnetospheric electron fluxes (Anderson 1965) which led Davis and Sugiura to suggest that these two phenomena are somehow linked. These findings, which already give some promises regarding the power of $A E$ indices, have been confirmed and further refined in dozens of later studies utilizing long term records of $A E$ alone or together with other data sets. During recent years $A E$-indices have been used annually at least in 30-40 publications addressing a wide variety of different topics in solar-terrestrial physics (http://wdc.kugi.kyoto-u.ac.jp/wdc/aedstcited.html).

$A E$-indices are produced by the WDC for Geomagnetism (Kyoto) from the horizontal magnetic field component $(H)$ recorded with 1-min time resolution at 10-13 magnetic observatories located under the average auroral oval in the Northern hemisphere (geomagnetic latitudes 60-70). Since the 1960s some variability has taken place in the contributing observatories, but the objective has always been to ensure a good coverage in all local time sectors with wellestablished observatories (For more details about the changes in the set-up of observatories, see the homepage of Kyoto AE-index service in World Data Center, http://wdc.kugi.kyoto-u.ac.jp/aedir/ae2/onAEindex.html. The current station distribution is presented in Figure 1). For an estimate of the disturbance magnetic field a baseline value is needed, which is derived monthly for each station by averaging its data recorded during the five international quietest days $(Q$-days). The lists of $Q$-days are available in http://wdc.kugi. kyoto-u.ac.jp/qddays and they are derived by GFZ (Potsdam) from the basis of $K p$-index values. Subtracting the baseline sets the data from all $A E$ stations to the same level and as the next step the maximum and minimum of all recorded $H$ are searched for each given time in UT. In other words, the upper and lower envelope curves are determined from the H-component magnetograms by the 10-13 observatories and these traces are defined to be the $A U$ and $A L$ indices which characterize the intensity of eastward and wesward electrojets, respectively. The difference, $A U-A L$, defines the $A E$-index, and the mean value of the $A U$ and $A L$, i.e. $(A U+A L) / 2$, defines the $A O$ index. $A E$-indices with time resolutions of $1 \mathrm{~min}, 2.5 \mathrm{~min}$ and $1 \mathrm{~h}$ are available from http://wdc.kugi.kyoto-u.ac.jp/aedir.

The physical background of $A E$-indices is associated with solar wind magnetosphere interactions and energy release processes in the magnetotail. Both 
these processes affect the intensity and spatial distribution of electric currents in the auroral oval region. When energy, momentum and particles are transferred from the solar wind to the magnetosphere due to viscous interaction or during dayside reconnection, usually both the eastward and westward electrojets experience a smooth enhancement (directly driven activity). A part of the energy from dayside reconnection gets stored in the magnetotail and dissipates after a while as an abrupt buildup of SCW to the ionosphere causing sudden enhancements in the westward electrojet (loading-unloading activity, i.e. geomagnetic substorms). These periods of rapid drops in $A L$ last typically 0.5-4 hours (McPherron 1970, 1979; Partamies et al. 2013) and the associated $A L$-minima values are often in the range from $-1000 \mathrm{nT}$ to $-300 \mathrm{nT}$. During geomagnetic storm periods with prolonged and intensive energy input from the solar wind $A L$-drops can even be below $-2000 \mathrm{nT}$, but in such cases the auroral oval also expands and electrojets shift to lower latitudes where the $A E$-stations cannot probe reliably their intensity anymore.

Allen and Kroehl (1975) conducted a statistical study on Magnetic Local Times (MLTs) of $A E$ observatories at the time instants when contributing to $A U$ or $A L$. This study is based on the observatory chain of 11 sites used in 1970. As mentioned above, some changes in the observatory locations have taken place since those days, but the results by Allen and Kroehl can still be considered as directional information on $A E$ properties in general . During active times the contributing station for $A U$ is typically in the MLT sector around 18 and that for $A L$ is around MLT 3. The statistics of Allen and Kroehl shows also secondary peaks in the distributions, which are around 6 MLT for $A U$ and 11 MLT for $A L$. The authors associate these peaks with quiet time currents appearing at sub-auroral latitudes. Substorm activity is known to concentrate to the midnight sector (e.g. Liou et al. (2001)), but as transient intensifications substorm expansion phases do not have the same weight in the statistics of contributing MLTs as persistent directly driven electrojet activity.

Long $A E$ data records provide a convenient way to study the efficiency of solar wind as activity generator in geospace. Different modes in the solar windmagnetosphere-ionosphere interactions have been recognized from $A E$ data. In addition to substorms the magnetospheric response can appear as pseudo breakups, steady magnetospheric convection, sawtooth injection events, poleward boundary intensification or as a mixture of these modes depending on the solar wind properties (McPherron 2015). Although the average appearance of these activations can be described, predicting their properties in individual cases is difficult, because coupling between solar wind and $A E$ variations is in significant amounts a stochastic process (Pulkkinen et al. 2006). The nonpredictable part of $A E$ has been investigated with different spectral analysis methods which have revealed that the $A E$-power spectrum exhibits power law behavior with a clear change in the slope at period times of $5 \mathrm{~h}$ (Tsurutani et al. 1990; Takalo et al. 1993). The study by Hnat et al. (2002) revealed that the scaling properties of $A L$ and $A U$ resemble those of Brownian walk for period times $<4 \mathrm{~h}$, which led the authors to associate the index variations in these times scales with turbulence in the solar wind. 
$A E$-indices have often been used in literature to construct empirical models which describe other geophysical parameters which are difficult to measure on global scales. For example, models for the size and location of the auroral oval as a function of the $A E$-index have been derived from meridional magnetometer data and from particle precipitation data (Rostoker and Phan 1986; Kauristie 1995). Spiro et al. (1982) have constructed empirical maps for electron energy flux and ionospheric conductances which both are dependent on $A E$-indices. These results have been utilized in the hemispheric Joule heating estimates by Baumjohann and Kamide (1984) who summarize their main result with a rough thumb rule where $1 \mathrm{nT}$ in $A E$ corresponds to $0.3 \mathrm{GW}$ in Joule Heating rate (for $A E<600 \mathrm{nT}$ ). Finding similar simple expressions for hemispheric auroral precipitation power has appeared to be challenging, because different dependencies are achieved from different measurement technologies. The empirical rule from space-based X-ray imager data by Østgaard et al. (2002) yield a larger power value for a given $A E$ than the model by Spiro et al. (1982) from satellite precipitation data, which again is larger than the estimate based on incoherent scatter radar measurements (Ahn et al. 1983).

\subsubsection{Regional AE-indices}

As stated above, the chain of $A E$-stations has problems to properly probe electrojet intensities during strong geomagnetic activity. This deficiency has motivated development of regional $A E$-indices, which use data from magnetometer networks which have a better latitudinal coverage than the $A E$-stations but a limited coverage in local time. In the context of auroral research such networks have been operated now for more than 20 years in North-American, Fennoscandian and Greenland local time sectors and along the geomagnetic longitude 210 .

The regional $A E$-indices based on the CANOPUS magnetometer network (Rostoker et al. 1995) were originally established to serve the research community of the NASA program on International Solar-Terrestrial Physics (ISTP). The CANOPUS network covered in late 1990s roughly 4 hours in MLT (NorthAmerican sector) and MLATs 61-74. One of the first papers utilizing $C L$ and $C U$ indices is the study by Lopez et al. (1998), where the indices are used as reference material for MHD simulation results addressing energy input and dissipation during a substorm period.

The concept of $I E$-indices based on the IMAGE magnetometer chain (Viljanen and Häkkinen 1997) was tested by Kauristie et al. (1996). The IMAGE chain used in that study covered magnetic latitudes 63-67 and roughly 0.5 hours in MLT (Fennoscandian sector). Even with this relatively limited fieldof-view, the IMAGE chain managed to capture westward (eastward) electrojet activity with a good accuracy (relative error less than 20\%) when probing MLT-sector 0000-0400 (1730-2230). IL(IU) provides improved performance when compared to $A L(A U)$ in MLT-sector 0030-0330 (1800-2200). IE indices have been used in several statistical studies addressing e.g. loading-unloading processes (Kallio et al. 2000) and geomagnetic induction effects at substorm 
onsets (Tanskanen et al. 2001). Although the data records of $I E$ indices are not as long as the $A E$-records, they gradually have become useful also in space climate studies (Tanskanen 2009).

\subsection{Currents in the polar cap and $P C$-index}

The concept of Polar Cap indices was originally introduced by Troshichev and Andrezen (1985) and revisited by Troshichev et al. (1988) and Vennerström et al. (1994). The concept has two indices, $P C N$ and $P C S$ for the Northern and Southern polar cap, respectively, which are derived using magnetometer recordings from stations Thule (MLAT $\sim 85$ ) and Vostok (MLAT $\sim-83$ ). The idea behind these indices is to estimate the intensity of antisunward plasma convection in the polar caps. This convection is associated with electric (Hall) currents and consequent magnetic field variations $(\Delta F) . \Delta F$ is the magnetic field component perpendicular to the antisunward flow (and related Hall current) which the Vostok and Thule magnetometers can measure. The scientific motivation for $P C$ measurements is to estimate continuously the energy input from solar wind to magnetosphere (loading activity). The index has been constructed so that it has a linear relationship with the Merging Electric Field, which according to Kan and Lee (1979) is determined as

$$
M E F=V B_{T} \sin ^{2}(\theta / 2)
$$

where $B_{T}$ is the transverse component of $I M F$, and $\theta$ is the angle between $B_{T}$ and the z-axis of the GSM coordinate system (for more details, see Kan and Lee (1979)). MEF characterizes magnetic reconnection rate at dayside magnetopause and it is defined to be always $\geq 0$. In general terms, large $M E F$ values are associated with southward magnetic field $\left(I M F B_{z}<0\right)$ and/or high speed of solar wind. For the purposes of internal magnetic field modelling often a revised version of $M E F$ is used (Newell et al. 2007; Olsen et al. 2014):

$$
M E F_{N}=0.33 V^{4 / 3} B_{T}^{2 / 3} \sin ^{8 / 3}(|\theta| / 2),
$$

The procedure to derive the $P C$-indices is rather complicated, when compared e.g. to the approach used in the derivation of $A E$-indices. The baseline level for $P C$-deviation must be determined with special care because the currents are much weaker in the polar cap than at the auroral oval latitudes. Harsh conditions in polar environment pose extra challenge for the continuity and stability of Vostok and Thule measurements. As only two stations are used, their position with respect to the polar cap plasma convection pattern varies according to UT, which must be taken into account in the index calculation routines. Due to these complications some iterations have been necessary in the work for a $P C$-concept which is transparent and stable enough for longterm statistical studies (Troshichev et al. 2006; Stauning 2007; McCreadie and Menvielle 2010; Stauning 2011, 2013). 
The relation between $P C, M E F$ and $\triangle F$ at Thule/Vostok can be expressed in the following form (Troshichev et al., 2006):

$$
P C=\xi \cdot M E F=\xi(\Delta F-\beta) / \alpha
$$

Here $\xi$ is a factor $(1 \mathrm{~m} / \mathrm{mV})$ to make $P C$ a dimensionless value which corresponds to $M E F$ values in $\mathrm{mV} / \mathrm{m} . \alpha$ and $\beta$ are parameters which come out from linear regression linking $\Delta F$ with MEF (Stauning 2007). $\Delta F$ can be related with $\Delta H$ and $\Delta D$ (magnetic field deviation measured in local magnetic coordinates): $\Delta F=\Delta H \sin (\gamma) \pm \Delta D \cos (\gamma)$, where $\gamma$ depends on UT, on geographic longitude and declination at the station, and on the angle $(\phi)$ between the average antisunward plasma flow direction and noon-midnight meridian. The value of $\phi$ depends on UT and on season. $P C$-indices are available in 1-min time resolution from an internet service (http://pc-index.org) which is maintained as collaboration of the Arctic and Antarctic Research Institute (Russia) and the Technical University of Denmark.

Harmonizing the $P C N$ and $P C S$ records has been a special challenge in the $P C$ refining work. In principle the estimates of $P C N$ and $P C S$ on $M E F$ should be consistent with each other. In practice, however, deviations between $P C N$ and $P C S$ appear even after rectifying some discrepancies in the past approaches used to generate the two data sets separately (Troshichev et al. 2006). Ionospheric conductances in the Northern and Southern polar caps differ from each other particularly during solstice times. Although major part of this effect is removed when the quiet time baseline is subtracted from $H$ and $D$, the remaining impact becomes visible when interhemispheric differences appear in the polar cap convection patterns due to a strong dawn-dusk component in $I M F$. In such cases large $P C$ values may appear although $M E F$ is close to zero. Periods of strong northward component in solar wind magnetic field can cause situations, where antisunward convection is replaced by sunward convection in the vicinity of Thule and/or Vostok and the $P C N$ and/or $P C S$ have negative values. With the original motivation for $P C$-index in mind ( $P C$ should be a proxy of $M E F$ and characterize magnetospheric loading activity) Stauning (2007) presents a definition for combined $P C(P C C)$ which is the average of values $\max [0, P C N]$ and $\max [0, P C S]$. As $P C C$ is by definition always positive like $M E F$, the correlation between $M E F$ and $P C C$ is higher than that for $P C N$ or $P C S$ (which vary in the range $0.6-0.9$, cf. Figure 2 in Stauning (2007)). A comprehensive review on the different PCS and $P C N$ datasets with their derivation methods and literature where the different versions have been used is presented by Stauning (2013).

$P C$ is not only related with the loading activity (substorm growth phase) but is responsive also to substorm expansion phases. With carefully selected events Huang (2005) demonstrates how PCN increases due to substorm onsets can be of the same order as increases due to $M E F$ enhancements, while the impact by pure pressure pulses in solar wind is visible but small $(P C N 1)$. Janzhura et al. (2007) compare the behavior of $P C$ in the summer and winter hemisphere (PCsum and PCwin) before and at the onsets of isolated substorms. Their results suggest that PCsum follows closely $M E F$ while PCwin 
is more sensitive to substorm intensifications. Like $A E$, also $P C N$ can be used as a proxy for the hemispheric Joule Heating $(J H)$ rate and the two estimates are highly correlated $(r>0.9)$ with each other (Chun et al. 1999). The relationship between $P C N$ and $J H$ rate is quadratic, while $P C N$ has a linear relationship with the hemispheric auroral precipitation power (Liou et al. 2003).

As the plasma flow is directly linked with the electric field in the ionosphere, $P C$ values should in principle correlate nicely with electric field measurements in the polar cap. Confirming this assumption with observations has appeared to be challenging. According to DMSP plasma velocity data a linear relationship between these parameters exists for small and moderate $P C$-values, but the electric field values appear to saturate at a level $\sim 50 \mathrm{mV} / \mathrm{m}$ when $P C \geq 10$ (Troshichev et al. 2000). SuperDARN radar electric field data shows signs of saturation already at $P C \geq 2$ (Fiori et al. 2009). According to radar data also the Cross Polar Cap Potential $(C P C P)$ saturates for $P C \geq 2$, while Akebono electric field data analysed by Troshichev et al. (1996) and statistics based on massive runs of the Assimilative Mapping of Ionospheric Electrodynamics technique, AMIE, show a linear relationship between $C P C P$ and $P C$ (Ridley and Kihn 2004). The techniques used in these studies all have some limiting factors (uncertainties in conductance estimates, spatial and temporal limitations in radar and satellite data) which complicate making the final conclusion on the $P C-C P C P$ relationship. Several studies anyway suggest that during strong activity the relationship between $M E F$ and ionospheric polar cap convection can be non-linear due to partial reflection of $M E F$ at the top of ionosphere (Gao et al. (2012) and references therein).

\section{Discussion}

According to Ritter et al. (2004) many of the commonly used magnetic indices have a poor performance in recognizing magnetically quiet times in the polar regions. Dst and $K p$ are more suitable for characterizing the inner magnetospheric current intensities than for estimating the intensity of high latitude ionospheric currents. The $P C$ and $I L$ indices have a slightly better performance, but only the combination of $M E F$ together with the solar zenith angle can provide reliable enough information for predictions of quiet time conditions. IL has obvious limitations in its longitudinal coverage which lowers its performance in the comparisons by Ritter et al., but it is not clear whether using the official AE instead of IL would improve the results significantly. AE has been designed to probe electrojet activity only in average conditions. Below we discuss different ways to improve the performance of AE-type indices and investigate how consistently different pairs of indices are able to describe weak activity levels. 


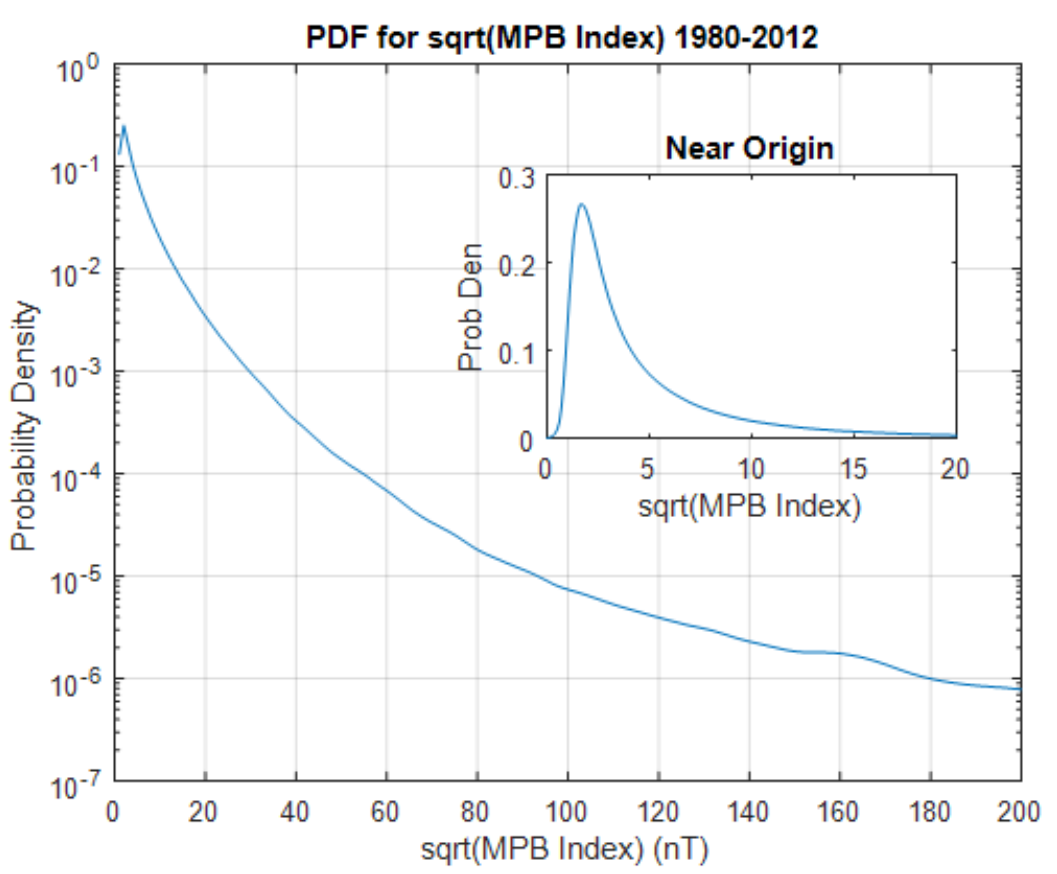

Fig. 7 The probability distribution function of $\sqrt{M P B}$ for the years 1980-2012. The bin size is $1 \mathrm{nT}(0.1 \mathrm{nT}$ for the insert). The data base used to create this plot includes more than 16 million one minute samples.

\subsection{Identifying substorm activity with the Midlatitude Positive Bay index}

The Midlatitude Positive Bay $(M P B)$-index developed by Chu et al. (2015) describes the intensity of SCW currents. According to its name $M P B$-index utilizes the magnetic signatures of SCWs at mid latitudes $\left(20^{\circ}<\mid\right.$ magn. lat. $\mid<$ $52^{\circ}$ ). These signatures are a northward deviation in the magnetic north component $(\mathrm{H})$ which is symmetric about the SCW central meridian and an antisymmetric deviation in the eastward component (D). $M P B$, which is expressed in unit $n T^{2}$, measures at different longitudes the difference of instantaneous magnetic field from its background level. For a more detailed description of $M P B$-index derivation we encourage the reader to study the accompanying paper by McPherron et al. in this issue.

Fig. 7 shows the PDF of $\sqrt{M P B}$ as derived from data collected during years the 1980-2012. This figure shows that the most probable value of $\sqrt{M P B}$ is $2 \mathrm{nT}$. Above that value the PDF falls off with a concave upward trend decreasing by five orders of magnitude at $200 \mathrm{nT}$. Close to $2 \mathrm{nT} \sqrt{M P B}$ is dominated by residual errors from background field subtraction. For reference we show in Fig. 8 the PDF of $A L$-index based on data from the years 1966-2013. Below about $-50 \mathrm{nT}$ the trace of $A L \mathrm{PDF}$ becomes a straight line suggesting a Poisson process. Above this value the index is most likely contaminated by 
PDF for AL Index 1966-2013

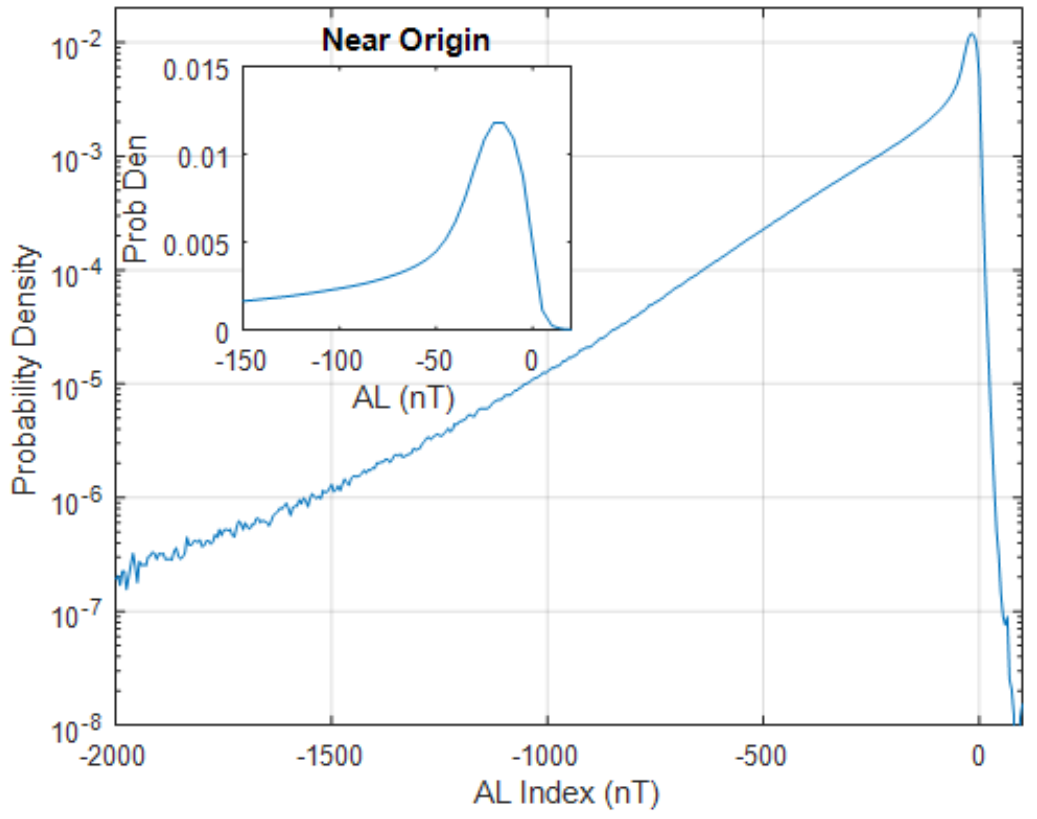

Fig. 8 The probability distribution function of $A L$ for the years 1966-2013. The bin size is $5 \mathrm{nT}$. The data base used to create this plot includes more than 23 million one minute samples.

shortcomings in the removal of quiet day variations. The different trends in the PDFs of $\sqrt{M P B}$ and $A L$ indicate that the two indices have a non-linear relation between them. Fig. 9 shows the conditional joint PDF of $\sqrt{M P B}$ and $A L$ for years $1980-2012$. In the $2 \mathrm{D}$ histogram each column tells the probability of $A L$ to be at the level of a given value in the ordinate with the condition of $\sqrt{M P B}$ having the value given in abscissa. The white line in the plot, which shows the median value of $A L$ for each $\sqrt{M P B}$, reveals the saturation of $A L$ to the level from -700 to $-750 \mathrm{nT}$ for $\sqrt{M P B}$ values above $50 \mathrm{nT}$. Investigation of the joint non-conditional PDF function of $\sqrt{M P B}$ and $A L$ (not shown here) reveals that the probability of conditions $\sqrt{M P B}<20 \mathrm{nT}$ and $A L>-100 \mathrm{nT}$ to take place simultaneously is $61 \%$. However, the PDFs also show that a small value of either index alone is insufficient to guarantee that the other index will also be small.

When identifying substorms, $M P B$-index has some advantages when compared to $A E$ : As $M P B$ is based on mid-latitude magnetometer data, it is more tolerant against changes in auroral oval size than $A E$. Also the longitudinal coverage of $M P B$ is better than that of $A E$, because $M P B$ is based on data from 41 stations distributed evenly to cover all longitudes. The onset of a sharp negative bay in the auroral zone and a positive bay in mid latitudes are recognized proxies for the onset of substorm expansion phase. One high 


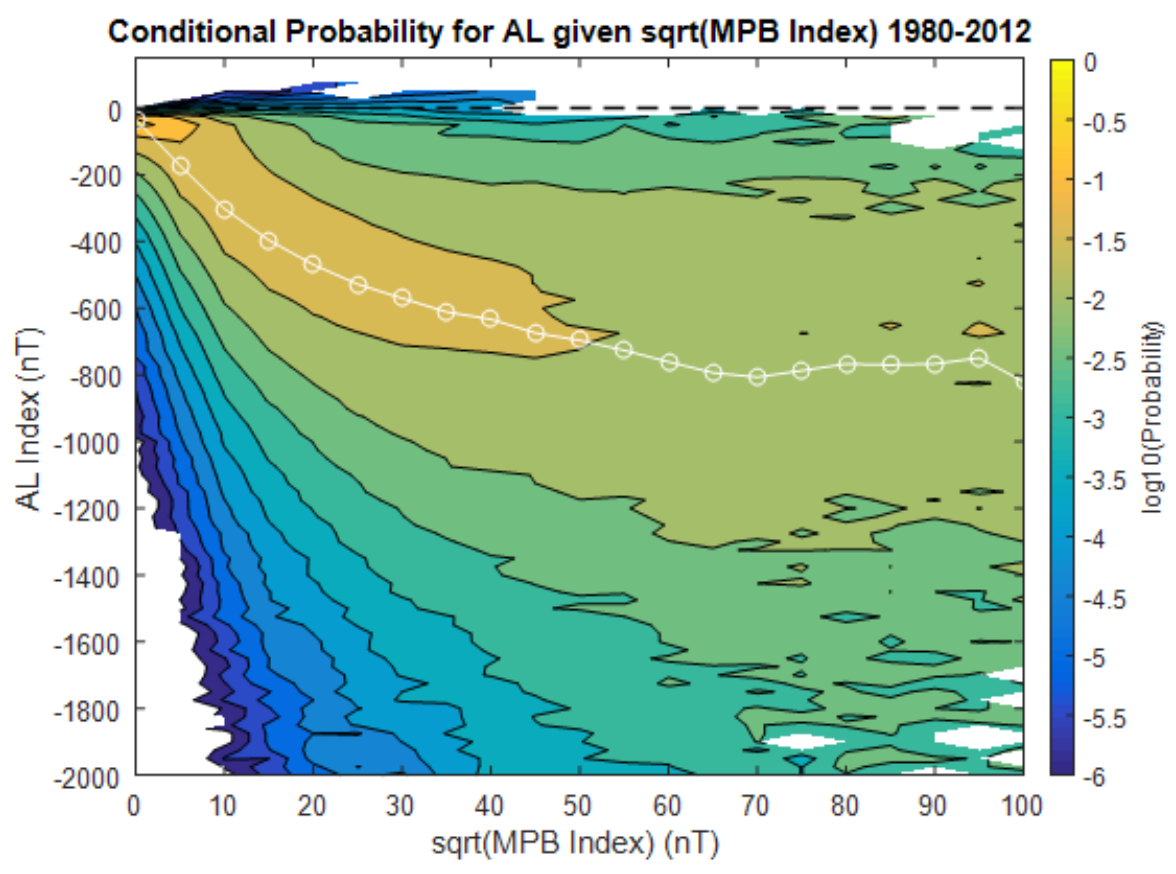

Fig. $92 \mathrm{D}$ histogram showing the conditional probability distribution function of $\sqrt{M P B}$ and $A L$ for years $1980-2012$. The bin size is $5 \mathrm{nT}$ for MPB and $25 \mathrm{nT}$ for $A L$. The histogram is based on more than 16 million pairs of data points. The white line shows the median AL (50 percentile) for each $M P B$ bin.

latitude list of negative bay onsets has been prepared from SuperMAG $A L$ (the index described in more detail below) by Newell and Gjerloev (2011a). A second list is that of Juusola et al. (2011) based on the official $A L$ index. A list of $M P B$ onsets has been prepared by Chu et al. (2015). Fig. 10 shows the waiting time distributions between substorm onsets as extracted from these three substorm lists. These distributions are very different as documented by annotation in the Figure. The differences are more associated with the different criteria used in onset determination than with the differences in the indices. In particular, the onsets by Juusola et al. (2011) should rather be considered as intensifications in substorm expansion than as beginnings of new events. Therefore, one substorm expansion phase as determined by Chu et al. (2015) can easily contain several onsets as determined by Juusola et al. (2011). Also the method by Newell and Gjerloev (2011a) seems to pick smaller intensifications than those found by Chu et al. (2015) as the SuperMAG onsets are clustered with very small delays between events with a mode in the waiting time at 23 minutes. The Juusola event list has a mode at 32 minutes and the $M P B$ list has a mode at 44 minutes. The mean values of these very asymmetric distributions are much larger with 142, 209, and 402 minutes for the official $A L$, SuperMAG $A L$, and $M P B$ lists. Sharp cutoffs near 30 minutes 
indicate the a priori assumption about the maximum rate at which substorms can occur used in the methods. As activations lasting less than 30 minutes are not considered to be full scale substorms the repetition rate of onsets is assumed to be longer than this threshold duration. The preference for longer waiting times in the $M P B$-distribution when compared to the two other distributions suggests that the method by $\mathrm{Chu}$ et al. (2015) tends to pick only substorms while the methods by Juusola et al. (2011) and Newell and Gjerloev (2011a) pick also other smaller activations, like pseudo breakups and poleward boundary intensifications.

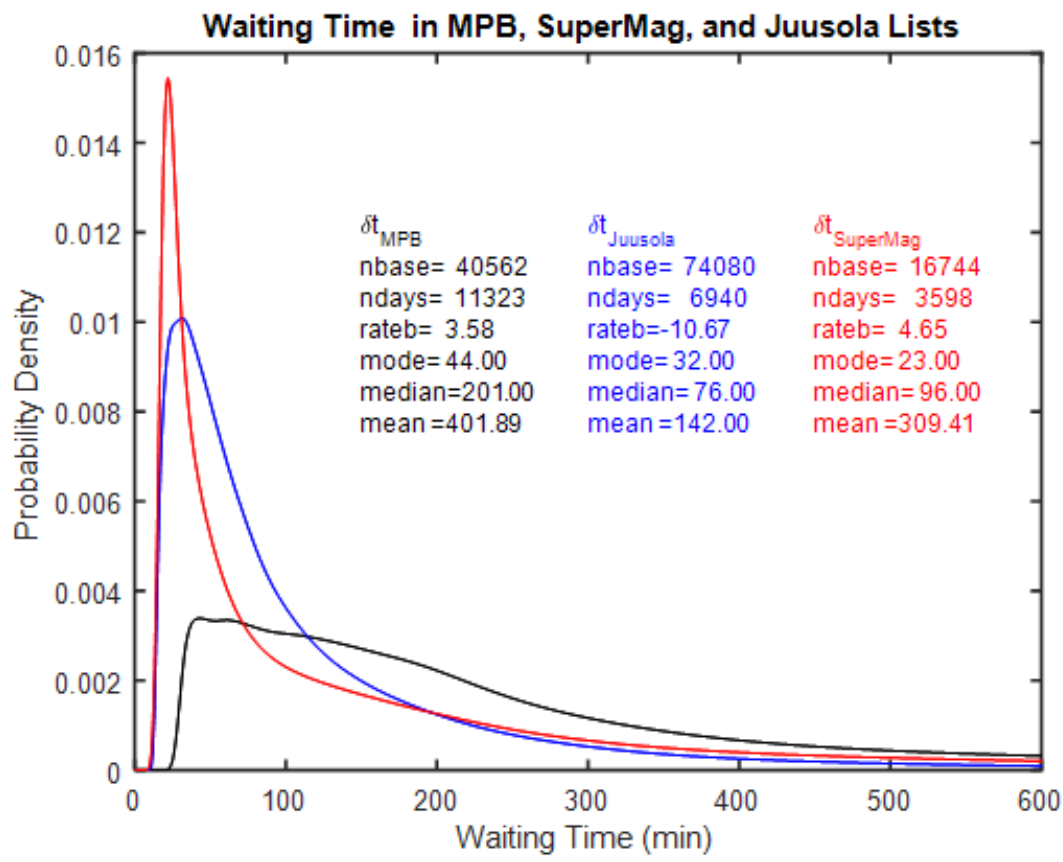

Fig. 10 The distributions of waiting time between substorm onsets as derived by Newell and Gjerloev (2011a) using the SuperMag $A L$ index, by Juusola et al. (2011) using the official $A L$ and by Chu et al. (2015) using the $M P B$ index.

\subsection{Opportunities provided by the SuperMAG derived indices}

Over the last few years a wave of new indices have been proposed and released through the SuperMAG initiative (Newell and Gjerloev 2011b,a, 2012, 2014). The basic motivation behind these indices is that the more stations used to derive the indices the better the current systems are monitored. The more stations the higher the probability that a station is in the right place at the 
right time. This consequently includes improved timing of changes in the currents, improved measure of the current intensity and improved information about the current location. Particularly for the $A E$-index, which is an envelope index, any extra station by definition will improve the accuracy. Based on this fact Opgenoorth et al. (1997) proposed to use data from automated magnetometer networks in addition to observatory data in order to monitor electrojet intensities in contracted, average and expanded auroral oval. This idea has been further refined and expanded in the SuperMAG concept, which produces auroral electrojet indices from the basis of $\sim 110$ stations. For monitoring of the ring current intensity SuperMAG offers an index which is based on $\sim 100$ stations (vs. the IAGA SYM-H index using six stations). These indices are available from http://supermag.jhuapl.edu/mag/. The SuperMAG approach obviously represents a break from the traditional way indices are derived. We briefly discuss six key differences:

- Traditionally the indices are derived from a fixed set of stations while the SuperMAG indices are derived from all available stations and thus a set of stations that is constantly changing. The advantage of a fixed set of stations is the consistency of the indices while the SuperMAG indices are derived from an ever changing set of stations. This, however, can also be viewed as a weakness of the traditional indices since they are based on a much smaller number of stations and thus are less likely to provide a correct measure of the current.

- Traditionally the indices are derived from a limited number of stations (12 or less) while the SuperMAG indices are derived from more than 100 stations. For the auroral electrojet indices which is a highly structured current distribution with large spatial gradients the many more stations unquestionably lead to an improved monitoring of the spatiotemporal behavior of the currents. An example was given by Newell and Gjerloev (2011a) which showed that the SuperMAG equivalent AE (SME) provided improved substorm onset timing, onset location and intensity.

- Traditionally the indices are global (time series of a scalar) while some SuperMAG indices are local time indices (time series of a vector). Newell and Gjerloev (2012) showed that the ring current should not be assumed to be a uniform current distribution and that large local time gradients exist in the storm main phase and first part of the recovery phase. They showed that the SuperMAG local time ring current indices (SMR-00, SMR-06, SMR-12, SMR-18) are not similar until the late recovery phase. Recently, Newell and Gjerloev (2014) introduced local time auroral electrojet indices but due to the much larger spatial gradients as compared to low latitudes they argued for 24 local time electrojet indices.

- Traditionally the indices vary in temporal resolution from 1 min to 3 hours while all SuperMAG indices are 1-min resolution. The purpose of the various indices is to provide a monitoring of the currents in questions. Thus, the indices must have an appropriate temporal resolution which exceeds the variability of the currents. For Kp which is a 3 hour index it is clearly not 
appropriate for monitoring the Magnetosphere-Ionosphere system which reconfigures in some 10-20 min. Similarly, the 1-hour Dst-index may have difficulties in monitoring rapid intensifications of the ring current during storm expansion phases.

- Traditionally the baseline and the processing of the data is done in segments and thus some changes in magnitude can be found between these segments while the SuperMAG indices are derived from data from which a continuous baseline is subtracted. Gjerloev (2012) published the technique used to remove the main field and the Sq current system. This technique is based on a statistical analysis of all the data and brakes with the classical quiet day approach (see Gjerloev (2012) for a lengthy discussion of these different techniques).

- Traditionally the indices are carefully quality checked by experienced personnel and denoted as final data while the SuperMAG indices are corrected as errors are identified. SuperMAG indices unquestionably have errors. For the auroral electrojet indices which are defined by a single station erroneous station data can unfortunately lead to erroneous indices. Although much effort is put into cleaning the station data, it is unavoidable that spikes and other artifacts are missed in the vast amount of data ( $>100$ stations and $>35$ years). In contrast the official AE-indices are validated and thus are void of these problems. On the other hand, in extensive statistical studies the harm resulting from randomly distributed artifacts may be less severe than the systematic bias due to limited coverage of observing points.

\subsection{How consistently do indices characterize quiet periods?}

Below we present a set of joint conditional PDF plots for different pairs of the above discussed geomagnetic indices with the goal to investigate their mutual consistency in describing quiet conditions. The 2D histograms show probability densities in the same way as presented in Fig. 9, i.e. each column tells the probability of the index in vertical axis to be at the level of a given value in the ordinate with the condition of the index in horizontal axis having the value given in abscissa. In contrast to Fig. 9 we use below linear scales in the color palettes. The values shown with the color palette are normalized so that integration along all bins in the vertical direction yields the value 100 (hence the $\%$-sign in the legend of the palette). The white dashed lines in the plots show the percentiles of 10, 30, 50, 70 and 90 (from bottom to top). The distribution of data points in the different bins is shown in the extra panels on top and right hand side of the 2D histograms.

Figs 11 and 12 show that $D$ st and its time derivative yield a largely similar picture as $K p$ on quiet conditions as determined with the conditions typically used in internal field modelling. With the condition of $K p=2$ approximately $90 \%$ of $|D s t|$ values are below $30 \mathrm{nT}$ and more than $70 \%$ of $|d D s t / d t|$ values are below $5 \mathrm{nT} / \mathrm{hr}$. With the condition of $K p=1 \sim 50 \%$ of $|d D s t / d t|$ are below $2 \mathrm{nT} / \mathrm{hr}$. 
Like concluded in Section 3.1 the values of $\sqrt{M P B}$ and $A L$ are not highly correlated with each other. If $\sqrt{M P B}$ is assumed to be $10 \mathrm{nT}$, which can be considered as weak activity but still above the threshold of background field contamination, then according to Fig. 9 roughly half of the $|A L|$-values are larger than $300 \mathrm{nT}$ (size of a small substorm or pseudo breakup). This information can be used as a reference to qualify the consistency between $A L$ and the other indices, i.e. $P C, K p$ and Dst. The corresponding conditional PDF plots are in Figs 13, 14 and 15. From these plots one can estimate that typical quiet time conditions used in field modelling for $P C(P C N<0.8), K p$ $(K p<2)$ and Dst $(|D s t|<30 n T)$ correspond to situations where only $\leq 10 \%$ of $|A L|$ values are above $200 \mathrm{nT}$ (for $P C$ ) or above $300 \mathrm{nT}$ (for $K p$ ) or to a situation where slightly less than $30 \%$ of $|A L|$ values are above $300 \mathrm{nT}$ (for $D s t)$. So all these indices seem to pick weak $A L$ activity with higher probability than the condition of $\sqrt{M P B}$ being $\sim 10 \mathrm{nT}$. The best correspondence appears to be between $P C$ and $A L$, which is consistent with the results of Vennerstrøm et al. (1991) who report high correlation values (0.8-0.9) between $P C N$ and $A E$ particularly during winter and equinox times.

Fig. 16 shows the conditional joint probability distribution function of $P C N$ and $K p$. With condition of $K p=2$ half of the $P C$ values are below 0.8. The percentile of 30 in Fig. 14 at the column of $\mathrm{Kp}=2$ corresponds to $A L \sim-100 n T$ which is equal to the situation where $\sim 70 \%$ of $|A L|$ values are less than $100 \mathrm{nT}$. Thus we can conclude that the condition of $\mathrm{Kp}=2$ is more often related with weak electrojet currents than with low $P C$ values.

Finally, Fig. 17 shows how often a longitudinally limited network of magnetometers at high latitudes (Svalbard stations of the IMAGE network) can see stronger auroral electrojet activity than the official $A L$ index. This can happen when the auroral oval is contracted or when the strongest activity appears near the poleward boundary of the oval. According to our data set with the condition of $A L$ being $\sim-50 \mathrm{nT}$ (i.e. no significant activity) $I L_{S V A}$ sees activity above the background level with $\sim 10 \%$ probability. In order to study the UT-dependency in the performance of $I L_{S V A}$ we binned the pairs of $A L$ and $I L_{S V A}$ data points to bins of 3-hours. Fig. 18 shows the PDF for the bin of 04-07 UT (corresponding to 0630-0930 in MLT), which was the bin of most remarkable differences when compared to the PDF without UT-binning. This figure reveals that under the condition of $A L=-50 n T \sim 30 \%$ of $I L_{S V A}$ values are below $-50 \mathrm{nT}$, i.e. almost in every third case, when $A L$ is only on the background level, the Svalbard stations record some distinct activations in the westward electrojet while they are probing the dawn sector of auroral oval.

\section{Summary and Conclusions}

Geomagnetic indices are commonly used in data selection criteria and in external field parametrization when internal (main) field models are developed. In this paper we give a review on geomagnetic indices describing global geo- 


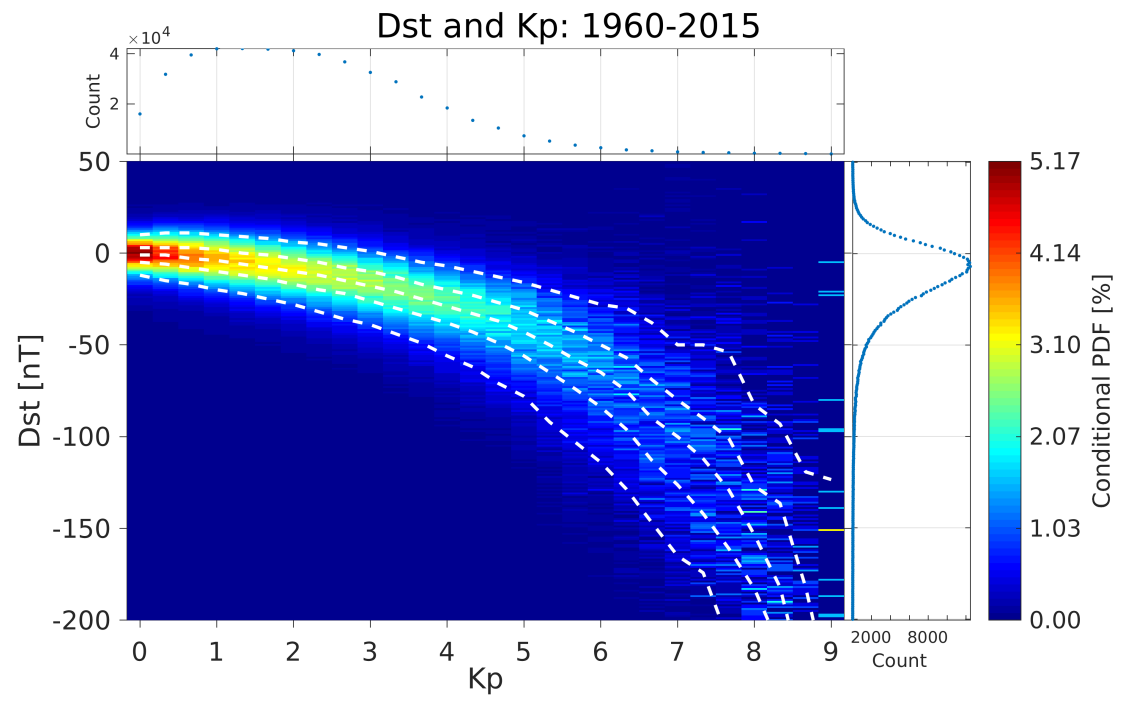

Fig. 11 2D histogram showing the conditional probability distribution function of $D s t$ and $K p$ with the bin sizes of $1 \mathrm{nT}$ and 0.33 , respectively.

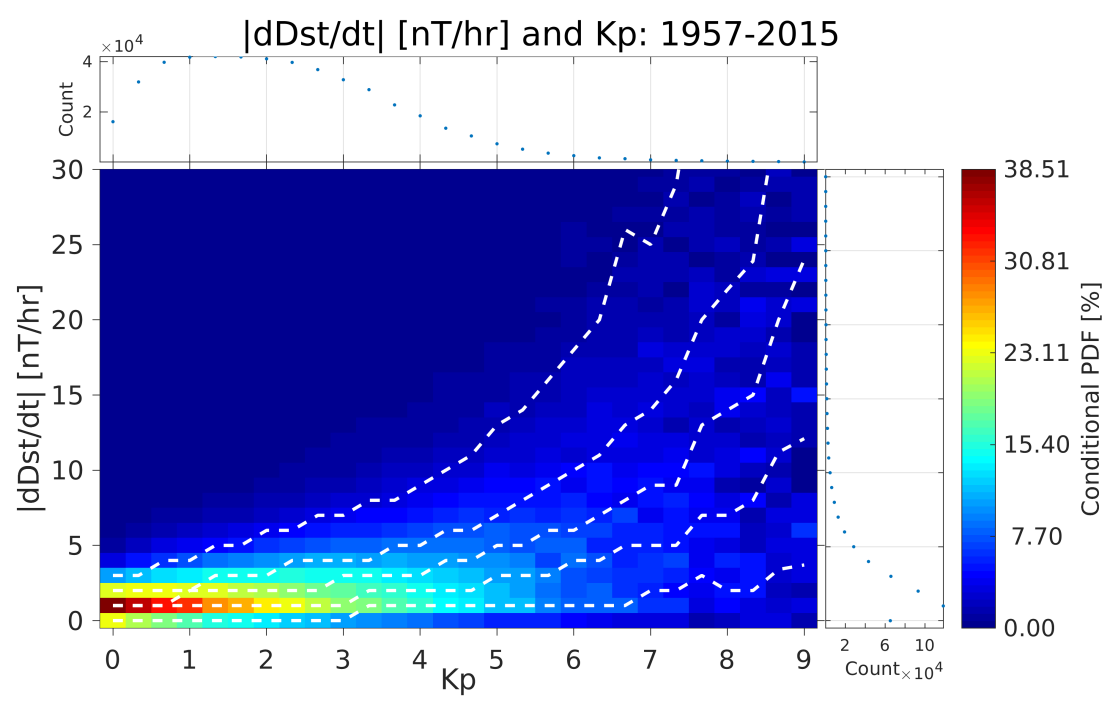

Fig. 12 2D histogram showing the probability distribution function $|d D s t / d t|$ and $K p$ with the bin sizes of $1 \mathrm{nT} / \mathrm{h}$ and 0.33 , respectively.

magnetic storm activity $(K p, a m, D s t$ and $d D s t / d t))$ and on indices designed to characterize high latitude currents and substorms ( $P C$ and $A E$-indices and their variants). We described the historical background and rationale behind these indices and gave a brief overview on their usage in solar-terrestrial physics and in main field modelling. Geomagnetic storm indices have been used more 


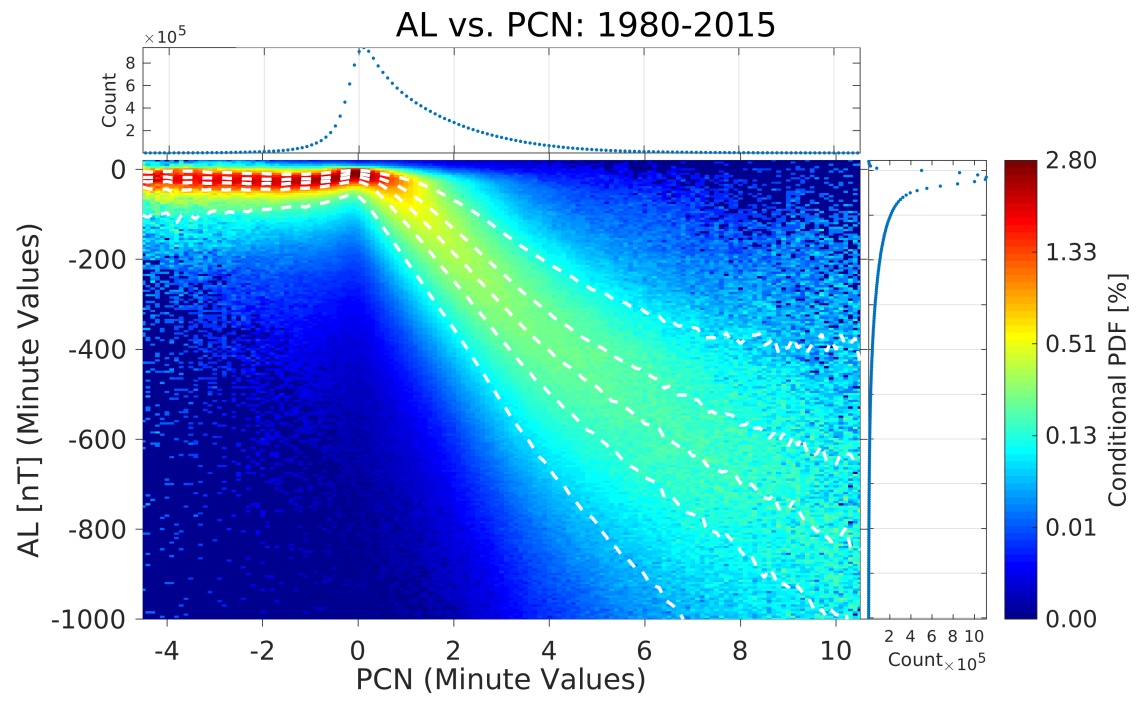

Fig. $132 \mathrm{D}$ histogram showing the conditional probability distribution between $A L$ and $P C N$ with the bin sizes of $5 \mathrm{nT}$ and 0.1 , respectively.

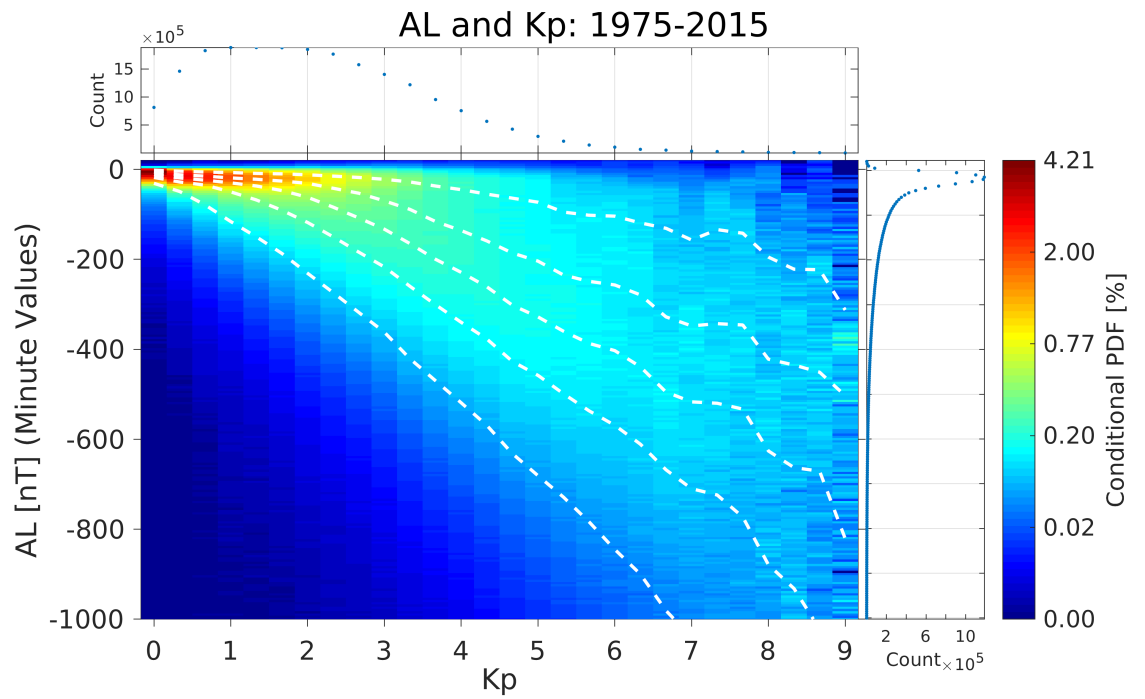

Fig. $142 \mathrm{D}$ histogram showing the conditional probability distribution between $A L$ and $K p$ with the bin sizes of $5 \mathrm{nT}$ and 0.33 , respectively.

extensively in internal field modelling than auroral electrojet and substorm indices. We have discussed the pros and cons of substorm indices and with the help of joint Probability Distribution Functions (PDFs) we demonstrate how accurately indices based on mid and low latitude measurements can discriminate magnetic quiescence from disturbed periods at high-latitudes. 


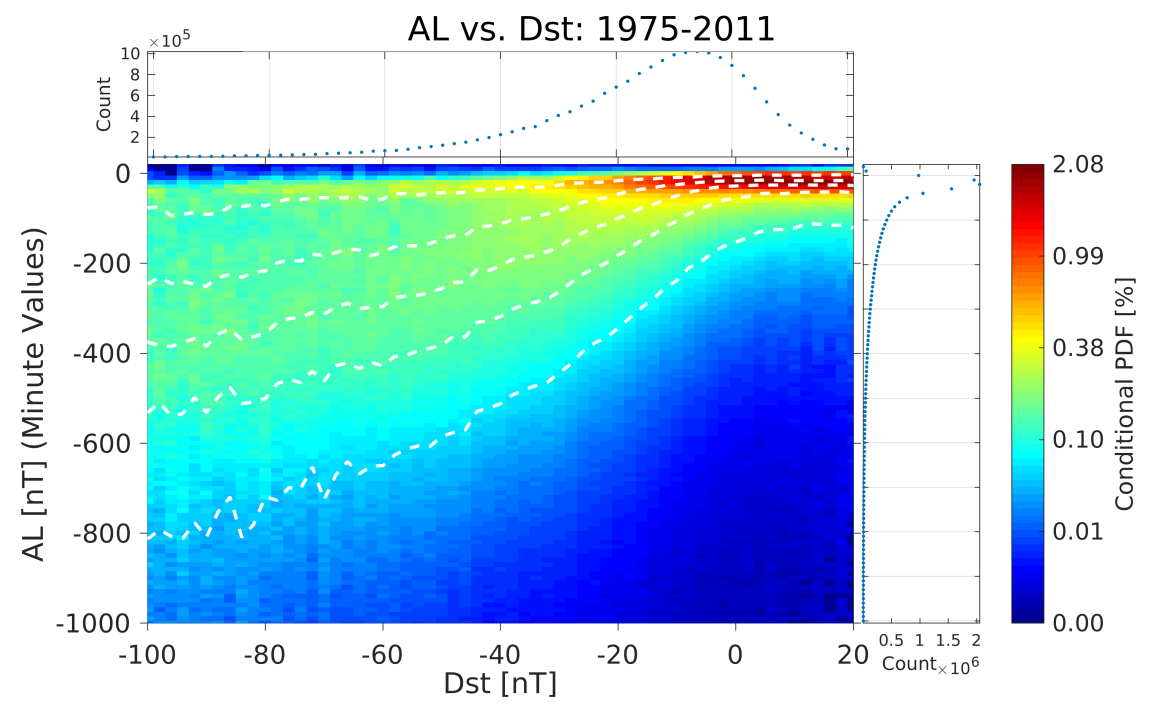

Fig. 15 2D histogram showing the conditional probability distribution between $A L$ and Dst with the bin sizes of $10 \mathrm{nT}$ and $2 \mathrm{nT}$, respectively.

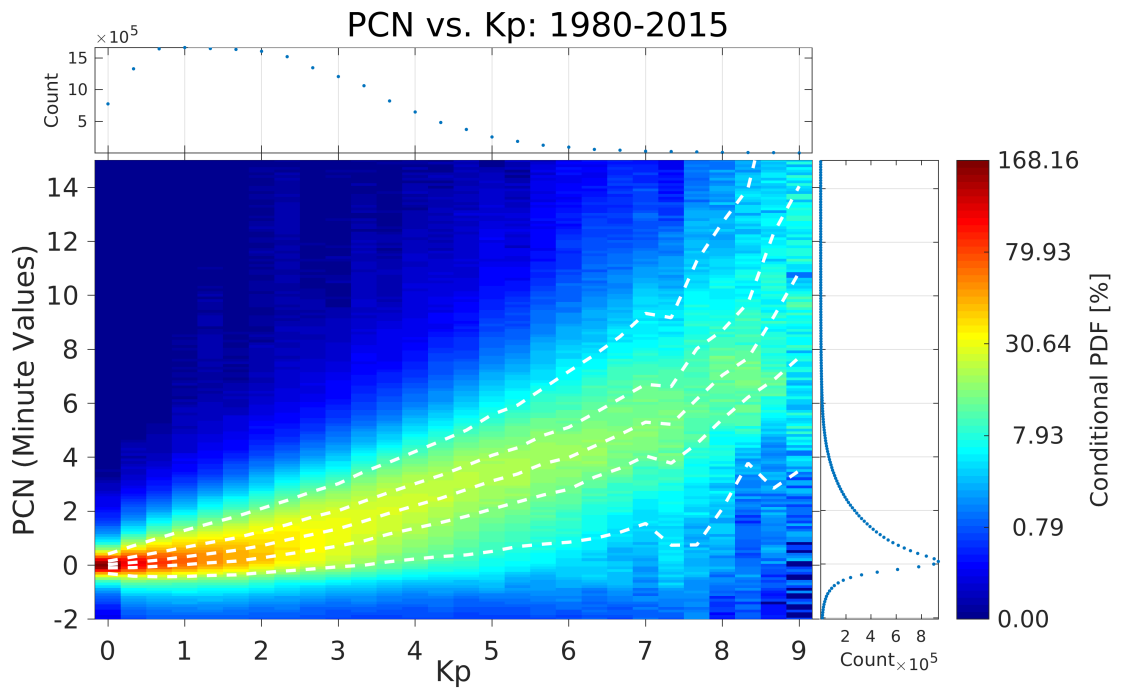

Fig. 16 2D histogram showing the conditional probability distribution between $P C N$ and $K p$ with the bin sizes of 0.1 and 0.33 , respectively.

The $K p$-index and its linear variant $A p$ are derived using data from 13 subauroral stations and they describe the global geomagnetic activity level with a time resolution of 3 hours. They provide a convenient way to investigate the linkage between solar and geomagnetic activity during several solar cycles and their variant, aa-index, has allowed investigations of solar variability even on 


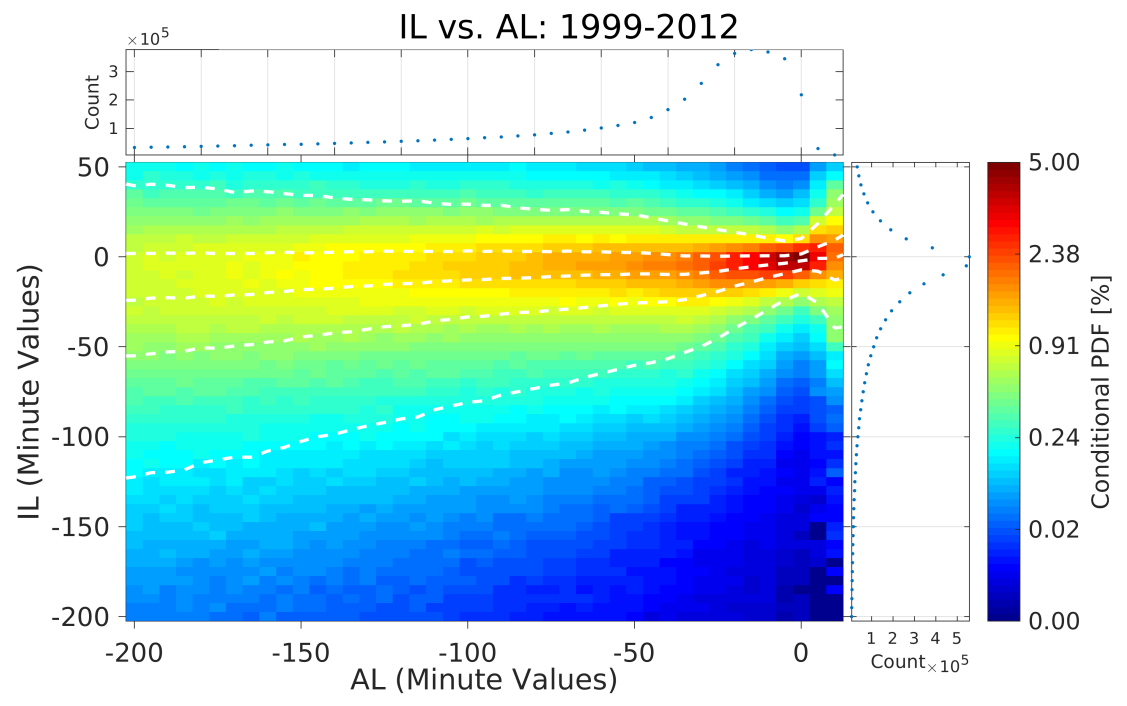

Fig. 17 2D histogram showing the conditional probability distribution between $I L$ and $A L$ constructed using only data from Svalbard magnetometer stations (magnetic latitudes 71.5-75). The bin size is $5 \mathrm{nT}$ for both indices.

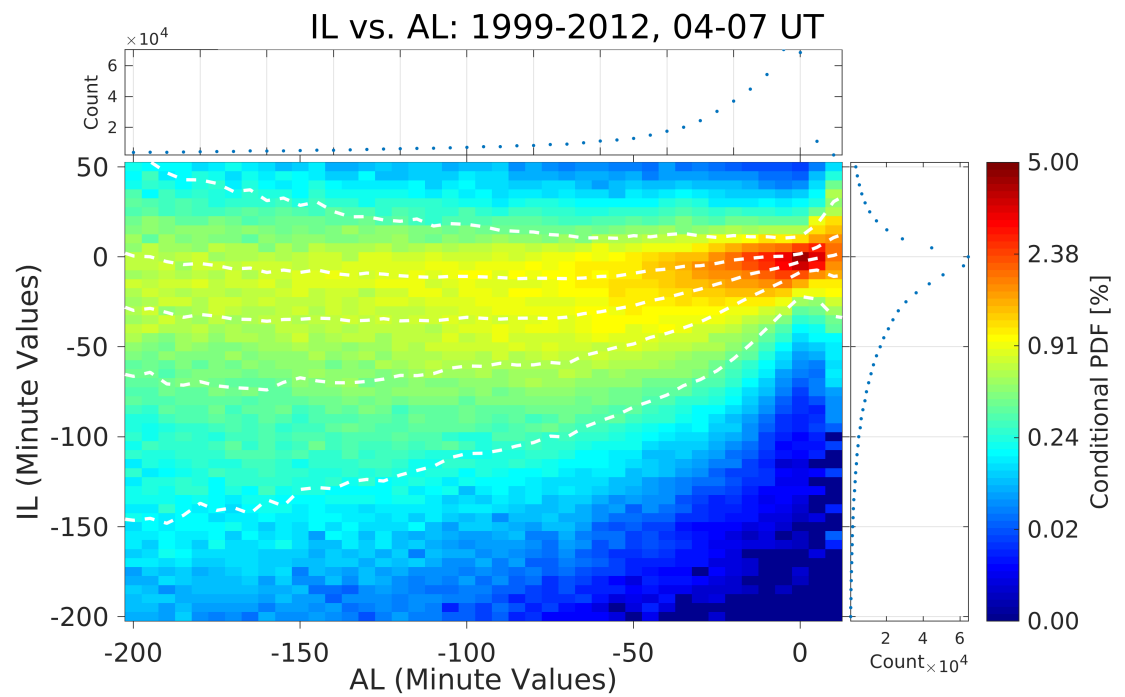

Fig. 18 2D histogram showing the conditional probability distribution between $I L$ and $A L$ constructed using data from Svalbard magnetometer stations (magnetic latitudes 71.5-75) recorded during 04-07 UT. The bin size is $5 \mathrm{nT}$ for both indices. 
centennial time scales. While years of minima in solar activity coincide with minima in geomagnetic activity, maxima in $K p$ or $A p$ values are delayed with $\sim 2$ years after the sunspot maxima. The annual probability distributions of $K p$ values have significant variability according to solar cycle.

The Dst-index and its variants aim to monitor variations of the equatorial magnetospheric ring current. The IAGA endorsed version of Dst is derived using data from four stations distant from the auroral and equatorial electrojets and approximately equally distributed in longitude. Although Dst was originally designed for geomagnetic storm studies, a number of its variants, with improved station coverage, time resolution and baseline correction, have been used to characterize specifically the quiet-time ring current. In internal field modelling advanced Dst-variants (e.g. $V D M$ and $R C$ indices) have a key role in characterizing the time dependence of the external field and the related induced currents below the ground surface. The separation of external and induced parts from a ground-based index is important for accurate estimates of its intensity at satellite altitudes.

The $A E$-indices are based on data from 10-13 magnetic observatories located under the average auroral oval in the Northern hemisphere (geomagnetic latitudes 60-70). They characterize the strength of eastward and westward electrojets in the evening and morning sectors of the oval and intensifications of the substorm current wedge in the midnight region. $A E$ provides a convenient way to study different modes in the solar wind-magnetosphereionosphere interactions (substorms, pseudo breakups, steady magnetospheric convection, sawtooth injection events, and poleward boundary intensification). As electrojet activity is closely linked with energy dissipation in the ionosphere, $A E$-indices have been used to construct empirical models for ionospheric conductances, for hemispheric Joule heating, and for auroral precipitation power. When the auroral oval is either very contracted (quiet times) or expanded (strong activity), $A E$-stations have problems in probing the electrojet activity reliably. This deficiency is the main reason for the little use of $A E$ in internal field modelling and it has motivated development of $A E$-variants based on improved station networks. The most expanded version of these variants comes from the SuperMAG concept, which produces auroral electrojet indices with $\sim 110$ stations.

The concept of $P C$-index has two indices, $P C N$ and $P C S$, which are derived using magnetometer recordings from two stations, Thule and Vostok. These stations are thought to measure the magnetic field variations caused by antisunward plasma convection in the polar caps. Enhanced polar cap convection is driven by magnetic reconnection at the dayside magnetopause. The reconnection rate can be measured with the Merging Electric Field $(M E F)$ and $P C$ index has been determined so that its value directly gives an estimate of $M E F$ in $\mathrm{mV} / \mathrm{m}$. As plasma convection in the polar cap is closely linked with auroral electrojet activity, $P C$ and $A E$ are highly correlated with each other in average conditions. Therefore $P C$ has been used for similar purposes as $A E$ in solar-terrestrial physics. In internal field modelling, however, $M E F$ as derived directly from solar wind data is preferred instead of $P C$ for high-latitude data 
selection routines. The usage of $M E F$ implies some assumptions about the propagation delay from the solar wind satellite location to polar ionosphere, but they are considered to be less harmful than the uncertainties in $P C$ or $A E$ usage resulting from the limitations in station coverage and in baseline corrections.

We have derived joint conditional PDF for different pairs of above discussed geomagnetic indices in order to see how consistently with each other they describe quiet conditions. An interesting topic for a continuation study would be a Principal Component Analysis addressing the whole set of indices simultaneously. Such approach would yield a broader view on similarities and differences between the indices and potentially reveal also new hybrid indices for improved description of high latitude external currents. Our PDF analysis yields the following conclusions:

- Dst and its time derivative yield a largely similar picture to $K p$ on quiet conditions as determined with the conditions typically used in internal field modelling. With the condition of $K p=2$ approximately $90 \%$ of $|D s t|$ values are below $30 \mathrm{nT}$ and more than $70 \%$ of $|d D s t / d t|$ values are below $5 \mathrm{nT} / \mathrm{hr}$.

- The quiet time conditions used in main field modelling for $M E F$ (here estimated with the condition $P C N<0.8), K p(K p<2)$ and Dst $(|D s t|<$ $30 \mathrm{nT}$ ) correspond to situations where only $\leq 10 \%$ of $|A L|$ values are above $200 \mathrm{nT}$ (for $P C$ ) or above $300 \mathrm{nT}$ (for $K p$ ) or to a situation where slightly less than $30 \%$ of $|A L|$ values are above $300 \mathrm{nT}$ (for $D s t$ ). So all these criteria correspond to weak $A L$ activity quite well: Standard size substorms are unlikely to happen, but other types of activations (e.g. pseudo breakups) can take place, when these criteria prevail.

- A small value of the Midlatitude Positive Bay -index $(\sqrt{M P B}<20 n T)$ does not necessarily imply that the $A E$-value will also be small. MPB anyway provides a convenient way to discriminate substorms from other more transient activations appearing in the auroral electrojets.

- With the condition of $K p=2 \sim$ half of the $P C$ values are below 0.8 and $\sim 70 \%$ of $|A L|$ values are less than 100 nT, i.e. the condition of $K p=2$ is more often related with weak electrojet currents than with low $M E F$ values.

- In $30 \%$ of the cases, when $A L$ is barely exceeding the threshold of significant activity $(A L=-50 n T)$, a regional $A L$-index based on Svalbard magnetometer stations (at magnetic latitudes 71.5-75) shows some distinct activations in the westward electrojet when the stations are probing the dawn sector of auroral oval.

In some of the newest modelling frameworks the amount of parameters describing external sources can be similar or even larger than that for internal field modelling (Sabaka et al. 2015). With this approach the impact of magnetospheric currents and ionospheric $S q$ and equatorial electrojet currents can be discriminated from the internal sources in the case of data collected during the satellite era. The advanced $D s t$-indices have a central role in this 
procedure. The official $A E$-indices do not have a similar position in the efforts to model the signal from high latitude currents. The existence of FACs at LEO altitudes breaks the condition of $\nabla \times \mathbf{B}=0$ at auroral latitudes, which poses an extra challenge for the attempts to model external currents there. An additional complication to this task comes from the large time variations in auroral currents. Advanced $A E$-variants may appear to be the most practical way to lower the elevated RMS-values which still exist in the residuals between modelled and observed values at high latitudes (Olsen et al. 2015). Recent initiatives to upgrade the $A E$-indices, either with a better coverage of observing stations and improved baseline corrections (the SuperMAG concept) or with higher accuracy in pinpointing substorm activity causing rapidly varying FACs and induction effects (the $M P B$-index) will most likely be helpful in these efforts. For example, a set of spatio-temporal basis functions as derived with Empirical Orthogonal Eigenfunction analysis from SuperMAG data may open a new way for describing high latitude activity in model parametrization.

Acknowledgements The authors are very grateful to the International Space Science Institute for inviting them to take part in the Workshop on "Earth's Magnetic Field" held in Bern in May 2015. The $I E$-indices of Svalbard magnetometer stations were prepared and provided by Liisa Juusola, Max Van de Kamp (FMI) and Noora Partamies (UNIS), Discussions about the $K p$ procedure have been conducted with Lasse Häkkinen and Ari Viljanen (FMI). TGO/University of Troms $\varnothing$ is acknowledged for maintaining the Svalbard stations. The Referees are acknowledged particularly for their fascinating ideas on future work under the topic of this paper.

\section{References}

B.-H. Ahn, S.-I. Akasofu, Y. Kamide, The Joule heat production rate and the particle energy injection rate as function of the geomagnetic indices $\mathrm{AE}$ and AL. JGR 88(A8), 6275-6287 (1983). doi:10.1029/JA088iA08p06275/. http://onlinelibrary.wiley.com/doi/10.1029/JA088iA08p06275/pdf

J.H. Allen, H.W. Kroehl, Spatial and temporal distributions of magnetic effects of auroral electrojets as derived from AE indices. J. Geophys. Res 80(25), 3667-3677 (1975). doi:10.1029/ja080i025p03667. http://dx.doi.org/10.1029/JA080i025p03667

K.A. Anderson, Radial dependence of energetic electron fluxes in the tail of the earth's magnetic field. Phys. Rev. Lett. 14, 888-890 (1965). doi:10.1103/PhysRevLett.14.888. http://link.aps.org/doi/10.1103/PhysRevLett.14.888

K.B. Baker, S. Wing, A new magnetic coordinate system for conjugate studies at high latitudes. J. Geophys. Res. 94(A7), 9139-9143 (1989). doi:10.1029/JA094iA07p09139. http://onlinelibrary.wiley.com/doi/10.1029/JA094iA07p09139/epdf

W. Baumjohann, Y. Kamide, Hemispherical Joule heating and the AE indices. J. Geophys. Res. 89(A1), 383-388 (1984). doi:10.1029/JA089iA01p00383. http://onlinelibrary.wiley.com/doi/10.1029/JA089iA01p00383/pdf

S. Chapman, An outline of a theory of magnetic storms. Proceedings of the Royal Society of London. Series A, Containing Papers of a Mathematical and Physical Character, 61-83 (1918)

X. Chu, T.-S. Hsu, R.L. McPherron, V. Angelopoulos, Z. Pu, J.J. Weygand, K. Khurana, M. Connors, J. Kissinger, H. Zhang, O. Amm, Development and validation of inversion technique for substorm current wedge using ground magnetic field data. JGR 119, 1909-1924 (2014). doi:10.1002/2013JA019185 http://onlinelibrary.wiley.com/doi/10.1002/2013JA019185/full 
X. Chu, R.L. McPherron, T.-S. Hsu, V. Angelopoulos, Solar cycle dependence of substorm occurrence and duration: Implications for onset. JGR 120, 2808-2818 (2015). doi:10.1002/2015JA021104. http://onlinelibrary.wiley.com/doi/10.1002/2015JA021104/full

F.K. Chun, D.J. Knipp, M.G. McHarg, G. Lu, B.A. Emery, S. Vennerström, O.A. Troshichev, Polar cap index as a proxy for hemispheric joule heating. GRL 26(8), 1101-1104 (1999)

C.G. Constable, Parameter estimation in non-Gaussian noise. Geophys. J. 94, 131-142 (1988). http://gji.oxfordjournals.org/content/94/1/131.full.pdf+html?sid=6cf52bd6f6f8-4355-9607-65e16ac93b0b

T.N. Davis, M. Sugiura, Auroral electrojet activity index AE and its universal time variations. J. Geophys. Res. 71(3), 785-801 (1966). doi:10.1029/jz071i003p00785. http://dx.doi.org/10.1029/JZ071i003p00785

C.C. Finlay, S. Maus, C.D. Beggan, M. Hamoudi, F.J. Lowes, N.Olsen, E. Thébault, Evaluation of candidate geomagnetic field models for IGRF-11. EPS 62(10), 787-804 (2010)

C.C. Finlay, N. Olsen, L. Tøffner-Clausen, DTU candidate field models for IGRF-12 and the CHAOS-5 geomagnetic field model. Earth, Planets and Space 67, 114 (2015)

R.A.D. Fiori, A.V. Koustov, D. Boteler, R.A. Makarevich, PCN magnetic index and average convection velocity in the polar cap inferred from superDARN radar measurements. JGR 114, 07225 (2009). doi:10.1029/2008JA013964. http://onlinelibrary.wiley.com/doi/10.1029/2008JA013964/full

E. Friis-Christensen, H. Lühr, G. Hulot, Swarm: A constellation to study the earths magnetic field. EPS 58(4), 351-358 (2006)

J. Gannon, J. Love, USGS 1-min dst index. Journal of Atmospheric and Solar-Terrestrial Physics 73(2), 323-334 (2011)

Y. Gao, M.G. Kivelson, R.J. Walker, The linear dependence of polar cap index on its controlling factors in solar wind and magnetotail. JGR $\mathbf{1 1 7}$ 05213 (2012). doi:10.1029/2011JA017229. http://onlinelibrary.wiley.com/doi/10.1029/2011JA017229/pdf

J.W. Gjerloev, The SuperMAG data processing technique. JGR 117, $09213 \quad$ (2012). doi:10.1029/2012JA017683. http://onlinelibrary.wiley.com/doi/10.1029/2012JA017683/full

L.V. Häkkinen, T.I. Pulkkinen, H. Nevanlinna, R.J. Pirjola, E.I. Tanskanen, Effects of induced currents on dst and on magnetic variations at midlatitude stations. Journal of Geophysical Research: Space Physics 107(A1) (2002)

B. Hamilton, Rapid modelling of the large-scale magnetospheric field from Swarm satellite data. Earth, Planets and Space 65, 1295-1308 (2013)

B. Hnat, S.C. Chapman, G. Rowlands, N.W. Watkins, M.P. Freeman, Scaling of solar wind $\epsilon$ and the AU, AL and AE indices as seen by WIND. GRL 29(22), 2078 (2002). doi:10.1029/2002GL016054. http://onlinelibrary.wiley.com/doi/10.1029/2002GL016054/full

C.-S. Huang, Variations of polar cap index in response to solar wind changes and magnetospheric substorms. JGR 110, 01203 (2005). doi:10.1029/2004JA010616. http://onlinelibrary.wiley.com/doi/10.1029/2004JA010616/full

T. Iyemori, Storm-time magnetospheric currents inferred from mid-latitude geomagnetic variations. J. Geomag. Geoelectr. 42, 1249-1265 (1990). doi:http://doi.org/10.5636/jgg.42.1249

A. Janzhura, O. Troshichev, P. Stauning, Unified PC indices: Relation to isolated magnetic substorms. JGR 112, 09207 (2007). doi:10.1029/2006JA012132. http://onlinelibrary.wiley.com/doi/10.1029/2006JA012132/full

L. Juusola, N. Østgaard, E. Tanskanen, N. Partamies, K. Snekvik, Earthward plasma sheet flows during substorm phases. JGR 116, 10228 (2011). doi:10.1029/2011JA016852. http://onlinelibrary.wiley.com/doi/10.1029/2011JA016852/full

E.I. Kallio, T.I. Pulkkinen, H.E.J. Koskinen, A. Viljanen, Loading-unloading processes in the nightside ionosphere. GRL 27(11), 1627-1630 (2000). doi:10.1029/1999GL003694. http://onlinelibrary.wiley.com/doi/10.1029/1999GL003694/pdf

J.R. Kan, L.C. Lee, Energy coupling function and solar wind - magnetosphere dynamo. GRL 6(7), 557-560 (1979). doi:10.1029/GL006i007p00577. http://onlinelibrary.wiley.com/doi/10.1029/GL006i007p00577/pdf 
A. Karinen, K. Mursula, A new reconstruction of the Dst index for 1932-2002, in Annales Geophysicae, vol. 23, Copernicus GmbH, 2005, pp. 475-485. Copernicus GmbH

K. Kauristie, Statistical fits for auroral oval boundaries during the substorm sequence. JGR 100(A11), 21885-21895 (1995). doi:10.1029/95JA01627. http://onlinelibrary.wiley.com/doi/10.1029/95JA01627/full

K. Kauristie, T.I. Pulkkinen, R.J. Pellinen, H.J. Opgenoorth, What can we tell about global auroral electrojet activity from a single meridional magnetometer chain? ANN 14(11), 1177-1185 (1996)

W. Kertz, Ein neues mass für die feldstärke des erdmagnetischen äquatorialen ringstroms. Abh. Akad. Wiss., Göttingen, Math. Phys., Beitr. zum Internat. Geophys. Jahr. 2, 1-83 (1958)

W. Kertz, Ring current variations during the IGY. Ann. Int. Geophys. Yr. 35 (1964)

M.G. Kivelson, C.T. Russell, Introduction to space physics (Cambridge University Press, Cambridge, 1995)

V. Lesur, I. Wardinski, M. Rother, M. Mandea, GRIMM: the GFZ reference internal magnetic model based on vector satellite and observatory data. Geophys. J. Int. 173, 382-294 (2008)

V. Lesur, I. Wardinski, M. Hamoudi, M. Rother, The second generation of the gfz reference internal magnetic model: GRIMM-2. EPS 62(10), 765-773 (2010)

J.V. Lincoln, Geomagnetic Indices, in Physics of Geomagnetic Phenomena, 1st Edition, International Geophysics Series, vol. 1, ed. by S. Matsushita, W.H. Campbell vol. 1 (Academic Press Inc., 111 Fifth Avenue, New York, New York 10003, 1967), pp. 67-98

K. Liou, P.T. Newell, D.G. Sibeck, C.-I. Meng, M. Brittnacher, G. Parks, Observation of imf and seasonal effects in the location of auroral substorm onset. JGR 106(A4), 5799-5810 (2001). doi:10.1029/2000JA003001. http://onlinelibrary.wiley.com/doi/10.1029/2000JA003001/epdf

K. Liou, J.F. Carbary, P.T. Newell, C.-I. Meng, O. Rasmussen, Correlation of auroral power with the polar cap index. JGR 108(A3), 1108 (2003). doi:10.1029/2002JA009556. http://onlinelibrary.wiley.com/doi/10.1029/2002JA009556/pdf

M. Lockwood, L. Barnard, H. Nevanlinna, M.J. Owens, R.G. Harrison, A.P. Rouillard, C.J. Davis, Reconstruction of geomagnetic activity and near-earth interplanetary conditions over the past $167 \mathrm{yr}$ - part 2: A new reconstruction of the interplanetary magnetic field. Ann. Geophysicae 31(11), 1979-1992 (2013). doi:10.5194/angeo-31-19792013. http://dx.doi.org/10.5194/angeo-31-1979-2013

R.E. Lopez, C.C. Goodrich, M. Wiltberger, K. Papadopoulos, Simulation of the March 9 , 1995 Substorm and Initial Comparison to Data, in Geospace Mass and Energy Flow: Results from the International Solar-Terrestrial Physics Program. Geophysical Monograph, vol. 104, 1998, pp. 237-245

J. Love, J. Gannon, Revised Dst and the epicycles of magnetic disturbance: 1958-2007, in Annales geophysicae: atmospheres, hydrospheres and space sciences, vol. 27, Citeseer, 2009, p. 3101. Citeseer

A.T.Y. Lui, C.D. Anger, A uniform belt of diffuse auroral emission seen by the ISIS-2 scanning photometer. PSS 21(5), 799 (1973). doi:10.1016/0032-0633(73)90097-4

S. Macmillan, N. Olsen, Observatory data and the Swarm mission. Earth, Planets and Space 65, 1355-1362 (2013)

S. Maus, H. Lühr, Signature of the quiet-time magnetospheric magnetic field and its electromagnetic induction in the rotating earth. GJI 162, 755-763 (2005). doi:10.1111/j.1365246X.2005.02691.x

S. Maus, P. Weidelt, Separating the magnetospheric disturbance magnetic field into external and transient internal contributions using a 1D conductivity model of the Earth Geophys. Res. Lett. 31 (2004). doi:10.1029/2004GL020232

S. Maus, C. Manoj, J. Rauberg, I. Michaelis, H. Lühr, NOAA/NGDC candidate models for the 11th generation international geomagnetic reference field and the concurrent release of the 6th generation pomme magnetic model. EPS 62(10), 729-735 (2010)

P.N. Mayaud, Derivation, Meaning, and Use of Geomagnetic Indices (Geophysical Monograph 22, American Geophysical Union, Washington, D.C., 1980)

P.N. Mayaud, Une mesure planétaire dactivité magnétique basée sur deux observatoires antipodaux. Ann. Geophysicae 27(1), 67-70 (1971) 
H. McCreadie, M. Menvielle, The PC index: review of methods. ANN, 1887-1903 (2010). http://www . ann-geophys . net/28/1887/2010/

R.L. McPherron, Earth's magnetotail, in Magnetotails in the Solar System, Geophysica Monograph 20\%, ed. by A. Keiling, C.M. Jackman, P.A. Delamere, American Geophysical Union, 2015, pp. 61-84

R.L. McPherron, Growth phase of magnetospheric substorms. J. Geophys. Res. $\quad \mathbf{7 5}(28), \quad 5592-5599 \quad$ (1970). doi:10.1029/ja075i028p05592. http://dx.doi.org/10.1029/JA075i028p05592

R.L. McPherron, Magnetospheric substorms. Rev. Geophys. 17(4), 657 (1979). doi:10.1029/rg017i004p00657. http://dx.doi.org/10.1029/RG017i004p00657

M. Menvielle, A. Berthelier, The K-derived planetary indices: Description and availability. Reviews of Geophysics 3(29), 415-432 (1991)

M. Menvielle, T. Iyemori, A. Marchaudon, M. Nosé, Geomagnetic Indices, in Geomagnetic Observations and Models (Springer, Dordrecht, The Netherlands, 2010), pp. 183-228

K. Mursula, A. Karinen, Explaining and correcting the excessive semiannual variation in the dst index. Geophysical research letters 32(14) (2005)

H. Nevanlinna, E. Kataja, An extension of the geomagnetic activity index series aa for two solar cycles (1844-1868). Geophys. Res. Lett. 20(23), 2703-2706 (1993). doi:10.1029/93gl03001. http://dx.doi.org/10.1029/93GL03001

P.T. Newell, J.W. Gjerloev, Evaluation of supermag auroral electrojet indices as indicators of substorms and auroral power. JGR 116, 12211 (2011a). doi:10.1029/2011JA016779. http://onlinelibrary.wiley.com/doi/10.1029/2011JA016779/full

P.T. Newell, J.W. Gjerloev, Substorm and magnetosphere characteristic scales inferred from the supermag auroral electrojet indices. JGR 116, 12232 (2011b). doi:10.1029/2011JA016936. http://onlinelibrary.wiley.com/doi/10.1029/2011JA016936/full

P.T. Newell, J.W. Gjerloev, SuperMAG-based partial ring current indices. JGR 117, 05215 (2012). doi:10.1029/2012JA017586. http://onlinelibrary.wiley.com/doi/10.1029/2012JA017586/full

P.T. Newell, J.W. Gjerloev, Local geomagnetic indices and the prediction of auroral power. JGR 119, 9790-9803 (2014). doi:10.1002/2014JA020524. http://onlinelibrary.wiley.com/doi/10.1002/2014JA020524/full

P.T. Newell, T. Sotirelis, K. Liou, C.-I. Meng, F.J. Rich, A nearly universal solar wind-magnetosphere coupling function inferred from 10 magnetospheric state variables. JGR 112(A1), 01206 (2007). doi:10.1029/2006JA012015. http://onlinelibrary.wiley.com/doi/10.1029/2006JA012015/full

N. Olsen, H. Lühr, T.J. Sabaka, M. Mandea, M. Rother, L. Toffner-Clausen, S. Choi, CHAOS - a model of the earth's magnetic field derived from CHAMP, /Orsted, and SAC-C magnetic satellite data. GJI 166, 67-75 (2006)

N. Olsen, M. Mandea, T.J. Sabaka, L. Toffner-Clausen, The CHAOS-3 geomagnetic field model and candidates for the 11th generation IGRF. EPS 62(10), 719-727 (2010)

N. Olsen, H. Lühr, C.C. Finlay, T.J. Sabaka, I. Michaelis, J. Rauberg, L. ToffnerClausen, The CHAOS-4 geomagnetic field model. GJI 197, 815-827 (2014). doi:10.1093/gji/ggu033

N. Olsen, G. Hulot, V. Lesur, C.C. Finlay, C. Beggan, A. Chulliat, T.J. Sabaka, R. Floberghagen, E. Friis-Christensen, R. Haagmans, S. Kotsiaros, H. Lühr, L. ToffnerClausen, P. Vigneron, The swarm initial field model for the 2014 geomagnetic field. GRL 42, 1092-1098 (2015). doi:10.1002/2014GL062659

N. Olsen, F. Lowes, T.J. Sabaka, Ionospheric and induced field leakage in geomagnetic field models, and derivation of candidate models for DGRF 1995 and DGRF 2000. Earth, Planets and Space 57, 1191-1196 (2005a)

N. Olsen, T.J. Sabaka, F. Lowes, New parameterization of external and induced fields in geomagnetic field modeling, and a candidate model for IGRF 2005. Earth, Planets and Space 57, 1141-1149 (2005b)

H.J. Opgenoorth, M.A.L. Persson, M. Lockwood, R. Stamper, M.N. Wild, R. Pellinen, T. Pulkkinen, K. Kauristie, T. Hughes, Y. Kamide, A new family of geomagnetic disturbance indices, in Ground-based observations in support of the Cluster mission, vol. ESA SP-1198, ed. by M. Lockwood, M.N. Wild, H.J. Opgenoorth (ESA Publications, ESTEC, 
Noordwijk, The Netherlands, 1997), pp. 49-62

N. Østgaard, R.R. Vondrak, J.W. Gjerloev, G. Germany, A relation between the energy deposition by electron precipitation and geomagnetic indices during substorms. JGR $\mathbf{1 0 7}(\mathrm{A} 9), 1246 \quad$ (2002). doi:10.1029/2001JA002003. http://onlinelibrary.wiley.com/doi/10.1029/2001JA002003/full

N. Partamies, L. Juusola, E. Tanskanen, K. Kauristie, Statistical properties of substorms during different storm and solar cycle phases. Ann. Geophys. 31(2), 349-358 (2013). doi:10.5194/angeo-31-349-2013. http://dx.doi.org/10.5194/angeo-31-349-2013

A. Pulkkinen, A. Klimas, D. Vassiliadis, V. Uritsky, Role of stochastic fluctuations in the magnetosphere-ionosphere system: A stochastic model for the AE index variations. JGR 111, 10218 (2006). doi:10.1029/2006JA011661. http://onlinelibrary.wiley.com/doi/10.1029/2006JA011661/full

A.D. Richmond, Ionospheric electrodynamics using magnetic apex coordinates. JGG 47, 191-212 (1995)

A.J. Ridley, E.A. Kihn, Polar cap index comparisons with amie cross polar cap potential, electric field, and polar cap area. GRL 31, 07801 (2004). doi:10.1029/2003GL019113. http://onlinelibrary.wiley.com/doi/10.1029/2003GL019113/epdf

P. Ritter, H. Lühr, S. Maus, A. Viljanen, High-latitude ionospheric currents during very quiet times: their characteristics and predictability. ANN 22, 2001-2014 (2004)

G. Rostoker, T.D. Phan, Variation of auroral electrojet spatial location as a function of the level of magnetospheric activity. J. Geophys. Res. 91(A2), 1716-1722 (1986). doi:10.1029/JA091iA02p01716. http://onlinelibrary.wiley.com/doi/10.1029/JA091iA02p01716/full

G. Rostoker, J.C. Samson, F. Creutzberger, T.J. Hughes, D.R. McDiarmid, A.G. McNamara, A. Vallance-Jones, D.D. Wallis, CANOPUS - a ground-based instrument array for remote sennsing the high latitude ionosphere during the ISTP/GGS program. SSR 71, 743-760 (1995)

T.J. Sabaka, N. Olsen, R.H. Tyler, A. Kuvshinov, CM5, a pre-swarm comprehensive geomagnetic field model derived from over 12 yr of CHAMP, /Orsted, SAC-C and observatory data. GJI 200, 1596-1626 (2015). doi:10.1093/gji/ggu493

M. Siebert, J. Meyer, Geomagnetic Activity Indices, in The Upper Atmosphere, ed. by W. Dieminger, G.K. Hartman, R. Leitinger (Springer, Berlin Heidelberg New York, 1996), pp. $887-911$

R.W. Spiro, P.H. Reiff, L.J.M. Jr., Precipitating electrn energy flux and auroral zone conductances - an empirical model. JGR 87(A10), 8215-8227 (1982). doi:10.1029/JA087iA10p08215. http://onlinelibrary.wiley.com/doi/10.1029/2006JA011661/full

P. Stauning, A new index for the interplanetary merging field and geomagnetic activity: Application of the unified polar cap indices. Space Weather 5, 09001 (2007). doi:10.1029/2007SW000311. http://onlinelibrary.wiley.com/doi/10.1029/2007SW000311/epdf

P. Stauning, Comment on "the PC index: review of methods", by mccreadie and menvielle (2010). ANNGEO 29, 1137-1146 (2011). doi:10.5194/angeo-29-1137-2011. http://www.ann-geophys.net/29/1137/2011/angeo-29-1137-2011.pdf

P. Stauning, The polar cap index: A critical review of methods and a new approach. JGR 118, 5021-5038 (2013). doi:doi:10.1029/jgra.50462 http://onlinelibrary.wiley.com/doi/10.1002/jgra.50462/pdf

M. Sugiura, IAGA resolution 2. IAGA Bulletin 27, 123 (1969)

M. Sugiura, T. Kamei, Equatorial $D_{s t}$-Index 1957-1986, in IAGA Bulletin $N^{\circ} 40$, ed. by A. Berthelier, M. Menvielle (ISGI Publ. Off., Saint. Maur-des-Fosses, France, 1991)

L. Svalgaard, Rederivation of Dst Index, in AGU Fall Meeting Abstracts, vol. 1, 2005, p. 04

L. Svalgaard, Geomagnetic semiannual variation is not overestimated and is not an artifact of systematic solar hemispheric asymmetry. Geophysical Research Letters 38(16) (2011)

L. Svalgaard, Correction of errors in scale values for magnetic elements for helsinki. Ann. Geophysicae 32(6), 633-641 (2014). doi:10.5194/angeo-32-633-2014. http://dx.doi.org/10.5194/angeo-32-633-2014

J. Takalo, J. Timonen, H. Koskinen, Correlation dimension and affinity of AE data and bicolored noise. GRL 20(15), 1527-1530 (1993). doi:10.1029/93GL01596. 
http://onlinelibrary.wiley.com/doi/10.1029/93GL01596/pdf

E.I. Tanskanen, A comprehensive high-throughput analysis of substorms observed by IMAGE magnetometer network: Years 19932003 examined. JGR 114, 05204 (2009). doi:10.1029/2008JA013682. http://onlinelibrary.wiley.com/doi/10.1029/2008JA013682/full

E.I. Tanskanen, A. Viljanen, T.I. Pulkkinen, R. Pirjola, L.H. andA. Pulkkinen, O. Amm, At substorm onset, $40 \%$ of AL comes from underground. JGR 106(A7), $13119 \quad$ (2001). doi:10.1029/2000JA900135. http://onlinelibrary.wiley.com/doi/10.1029/2000JA900135/full

M. Temerin, X. Li, The dst index underestimates the solar cycle variation of geomagnetic activity. Journal of Geophysical Research: Space Physics 120(7), 5603-5607 (2015)

E. Thébault, C.C. Finlay, P. Alken, C.D. Beggan, E. Canet, A. Chulliat, B. Langlais, V. Lesur, F.J. Lowes, C. Manoj, M. Rother, R. Schachtschneider, Evaluation of candidate geomagnetic field models for IGRF-12. EPS 67(112) (2015). doi:10.1186/s40623-0150273-4

A.W.P. Thomson, V. Lesur, An improved geomagnetic data selection algorithm for global geomagnetic field modelling. Geophys. J. Int. 169(3), 951-963 (2007)

O. Troshichev, A. Janzhura, P. Stauning, Unified PCN and PCS indices: Method of calculation, physical sense, and dependence on the imf azimuthal and northward components. JGR 111, 05208 (2006). doi:10.1029/2005JA011402. http://onlinelibrary.wiley.com/doi/10.1029/2005JA011402/full

O. Troshichev, H. Hayakawa, A. Matsuoka, T. Mukai, K. Tsuruda, Cross polar cap diameter and voltage as a function of $\mathrm{PC}$ index and interplanetary quantities. JGR 101(A6), 13429-13435 (1996). doi:10.1029/95JA03672. http://onlinelibrary.wiley.com/doi/10.1029/95JA03672/full

O.A. Troshichev, V.G. Andrezen, The relationship between interplanetary quantities and magnetic activity in the southern polar cap. PSS 33(4), 415-419 (1985). doi:10.1016/0032-0633(85)90086-8

O.A. Troshichev, V.G. Andrezen, S. Vennerström, E. Friis-Christensen, Magnetic activity in the polar cap - a new index. PSS 36(11), 1095-1102 (1988). doi:10.1016/00320633(88)90063-3

O.A. Troshichev, R.Y. Lukianova, V.O. Papitashvili, F.J. Rich, O. Rasmussen, Polar cap indec (PC) as a proxy for ionospheric electric field in the near-pole region. GRL 27(23), 3809-3812 (2000)

B. Tsurutani, M. Sugiura, T. Iyemori, B.E. Goldstein, W.D. Gonzalez, S.I. Akasofu, E.J. Smith, The nonlinear response of AE to the IMF BS driver: A spectral break at 5 hours. GRL 17(3), 279-282 (1990). doi:10.1029/GL017i003p00279. http://onlinelibrary.wiley.com/doi/10.1029/GL017i003p00279/full

N.A. Tsyganenko, A model of the near magnetosphere with a dawndusk asymmetry, 2, parameterization and fitting to observations. JGR 107(A8), 10-11017 (2002). doi:10.1029/2001JA000220. http://onlinelibrary.wiley.com/doi/10.1029/2001JA000220/full

S. Vennerstrøm, E. Friis-Christensen, O.A. Troshichev, V.G. Andresen, Comparison between the polar cap index, $P C$, and the auroral electrojet indices, $A E, A L$, and $A U$. J. Geophys. Res. 96, 101-113 (1991)

S. Vennerström, E. Friis-Christensen, O.A. Troshichev, V.G. Andrezen, Geomagnetic polar cap (PC) index 1975-1993, Rep. UAG-103, World Data Center A, Boulder, Colorado, 1994

A. Viljanen, L. Häkkinen, IMAGE magnetometer network, in Ground-based observations in support of the Cluster mission, vol. ESA SP-1198, ed. by M. Lockwood, M.N. Wild, H.J. Opgenoorth (ESA Publications, ESTEC, Noordwijk, The Netherlands, 1997), pp. $111-117$

J.A. Wanliss, K.M. Showalter, High-resolution global storm index: Dst versus SYM-H. Journal of Geophysical Research: Space Physics (1978-2012) 111(A2) (2006) 